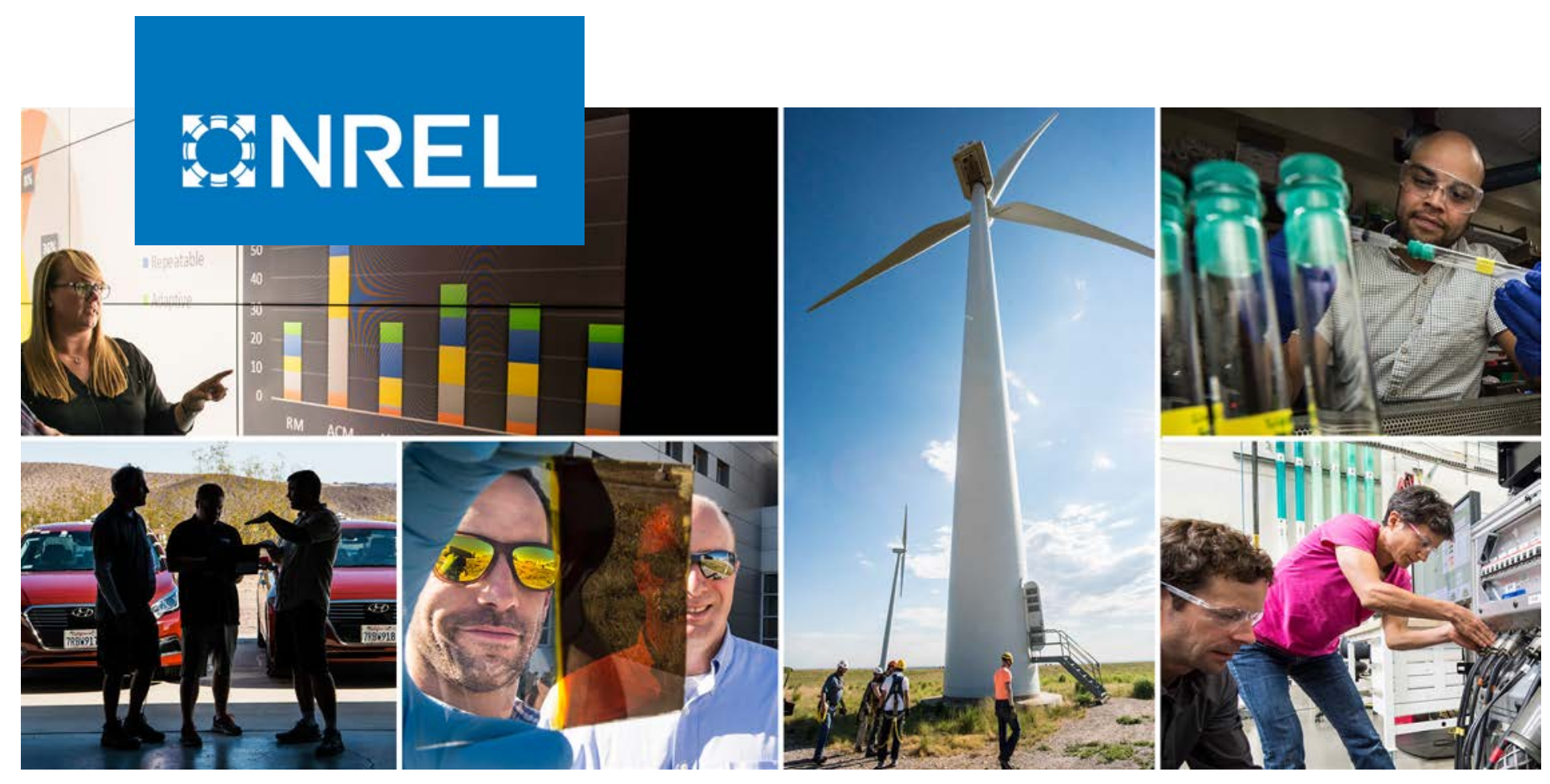

\title{
Adapting Existing Energy Planning, Simulation, and Operational Models for Resilience Analysis
}

Caitlin Murphy, Eliza Hotchkiss, Kate Anderson, Clayton Barrows, Stuart Cohen, Sourabh Dalvi, Nick Laws, Jeff Maguire, Gord Stephen, and Eric Wilson

NREL is a national laboratory of the U.S. Department of Energy Office of Energy Efficiency \& Renewable Energy

Operated by the Alliance for Sustainable Energy, LLC

This report is available at no cost from the National Renewable Energy Laboratory (NREL) at www.nrel.gov/publications.

\section{Technical Report}

NREL/TP-6A20-74241

February 2020 


\title{
BNREL
}

\section{Adapting Existing Energy Planning, Simulation, and Operational Models for Resilience Analysis}

\author{
Caitlin Murphy, Eliza Hotchkiss, Kate Anderson, \\ Clayton Barrows, Stuart Cohen, Sourabh Dalvi, Nick Laws, \\ Jeff Maguire, Gord Stephen, and Eric Wilson
}

\section{Suggested Citation}

Murphy, Caitlin, Eliza Hotchkiss, Kate Anderson, Clayton Barrows, Stuart Cohen, Sourabh Dalvi, Nick Laws, Jeff Maguire, Gord Stephen, and Eric Wilson. 2020. Adapting Existing Energy Planning, Simulation, and Operational Models for Resilience Analysis. Golden, CO: National Renewable Energy Laboratory. NREL/TP-6A20-74241.

https://www.nrel.gov/docs/fy20osti/74241.pdf.

NREL is a national laboratory of the U.S. Department of Energy Office of Energy Efficiency \& Renewable Energy Operated by the Alliance for Sustainable Energy, LLC

This report is available at no cost from the National Renewable Energy Laboratory (NREL) at www.nrel.gov/publications.

Contract No. DE-AC36-08GO28308
Technical Report

NREL/TP-6A20-74241

February 2020

National Renewable Energy Laboratory 15013 Denver West Parkway Golden, CO 80401 303-275-3000 • www.nrel.gov 


\section{NOTICE}

This work was authored by the National Renewable Energy Laboratory, operated by Alliance for Sustainable Energy, LLC, for the U.S. Department of Energy (DOE) under Contract No. DE-AC36-08GO28308. Funding provided by a Laboratory Directed Research and Development investment at NREL. The views expressed herein do not necessarily represent the views of the DOE or the U.S. Government.

This report is available at no cost from the National Renewable Energy Laboratory (NREL) at www.nrel.gov/publications.

U.S. Department of Energy (DOE) reports produced after 1991 and a growing number of pre-1991 documents are available free via www.OSTI.gov.

Cover Photos by Dennis Schroeder: (clockwise, left to right) NREL 51934, NREL 45897, NREL 42160, NREL 45891, NREL 48097, NREL 46526.

NREL prints on paper that contains recycled content. 


\section{Acknowledgments}

This analysis benefited greatly from thoughtful comments and suggestions from several colleagues who generously reviewed either the entire report or portions of it in draft form. The authors thank Mercy DeMenno from Bosque Advisors for Sandia National Laboratory, Wilson Rickerson from Converge Strategies, and Jordan Cox, Sean Ericson, and Daniel Steinberg from the National Renewable Energy Laboratory (NREL).

This work was authored by the NREL, operated by Alliance for Sustainable Energy, LLC, for the U.S. Department of Energy (DOE) under Contract No. DE-AC36-08GO28308. This work was supported by the Laboratory Directed Research and Development (LDRD) Program at NREL. The views expressed in the article do not necessarily represent the views of the DOE or the U.S. Government. The U.S. Government retains and the publisher, by accepting the article for publication, acknowledges that the U.S. Government retains a nonexclusive, paidup, irrevocable, worldwide license to publish or reproduce the published form of this work, or allow others to do so, for U.S. Government purposes. 


\section{Executive Summary}

Resilience is a topic receiving much attention in relation to energy systems, with particular attention being paid to the supply of electricity. Within the context of the electricity system, definitions of resilience encompass holistic concepts that emphasize preparing for, absorbing, adapting to, and recovering from interruptions in electricity supply (White House 2013; DHS 2013; Hotchkiss and Dane 2019; Watson et al. 2014; Stankovic and Tomsovic 2018). Recent research has focused on understanding the resilience of the electricity sector to a core set of disruptions, which reflects (1) the economy's increased dependence on electricity, (2) multiple emerging threats to the system (e.g., severe weather, aging infrastructure, cyberattacks, and physical attacks), and (3) the rapid evolution of the electricity system in recent decades (National Academies of Sciences, Engineering, and Medicine 2017). However, disruptions that test the resilience of a system or community can result in largescale consequences, as opposed to being constrained to a single sector or service type.

As a result of the growing interest in electricity sector resilience, research communities have proposed a plethora of candidate resilience indicators and metrics, most of which remain immature at different scales and segments within the energy system. Given the complexity of resilience analyses and mitigation strategies, there is limited value in attempting to identify a single resilience metric, as no one metric can quantify resilience or its associated value for all stakeholders. Instead, a necessary focus of the research community should lie in implementing, testing, and validating resilience metrics and analysis approaches in energy sector models, which will be invaluable for informing resilience planning and investment decisions.

Recognizing these challenges that need to be addressed, we explored how to effectively integrate resilience considerations into energy sector models and tools. The overarching goal of the effort was to evaluate the data needs, methodologies, and outcomes-including consequences and/or changes in investment or operational decisions due to avoided consequences - for resilience analysis in a range of existing tools. In particular, we selected five models - originally built at NREL to explore non-resilience energy research questions - in which to implement and exercise resilience metrics and analysis approaches.

To demonstrate the importance of perspective, we selected models that represent different segments of the energy sector, geographic scales, and modeling approaches. The ultimate set of models selected spans simulations of building stocks and campus-level backup power systems, to the bulk power system across the contiguous United States. In addition, to explore different approaches for implementing a chosen resilience metric, we chose tools with very different modeling approaches, including (1) optimization for both long-term planning and electricity dispatch and (2) detailed simulations of energy system performance under adverse conditions.

A second important aspect of our effort was the development of generalized power interruption scenarios. These scenarios were intended to help establish a framework for simulating the effects of real-world threats in terms of their impacts on system components and, in turn, power interruption. In this case, the term "threat" refers to something that could negatively impact a part of the energy system, and threats were defined based on variations across two dimensions: (1) whether system operators have time to prepare and (2) the duration of the associated power interruption. 
Based on their chosen resilience metric and power interruption scenario, each modeling team performed a preliminary resilience analysis. Similar resilience analyses could be replicated in future research that seeks to explore questions related to these preliminary results and findings, which are summarized here:

1. The ResStock tool simulates energy use in housing stocks at national, regional, or local scales. Based on research completed under this study, ResStock can now simulate a power interruption, and it can evaluate the thermal resilience of the residential building stock during a power interruption that is coincident with adverse weather conditions. Initial results showed that more-efficient buildings tend to be more-resilient because they can maintain livable indoor temperatures longer during interruptions in the supply of electricity or natural gas.

2. The Probabilistic Resource Adequacy Suite (PRAS) simulates outage events on the bulk power system to quantify the risk of unserved load events resulting from shortfalls in the supply or deliverability of capacity. Under this study, PRAS was used to evaluate how the deployment of energy storage on a regional grid could impact the resilience of the system during a multiday disruption of fuel supply for natural gas generators. Initial results showed that adding energy storage devices could reduce the depth of shortfall, as quantified by the expected unserved energy metric applied to a 58-hour fuel supply disruption scenario.

3. The Scalable Integrated Infrastructure Planning Power Systems Toolkit (SIIP::Power) provides a flexible framework for defining and solving power systems analysis problems, including a variety standard unit commitment and economic dispatch formulations. As a result of research completed under this study, SIIP::Power can now model a value of lost load that varies (a) over the duration of a power interruption and (b) by node. SIIP::Power uses this information to select which buses to serve at each time-step when there is not enough energy to serve all loads in order to minimize total system cost (including both outage and generation costs). Exercising the production cost modeling framework in SIIP::Power with this duration-dependent value of lost load results in operational differences, such that the total level of lost load (in megawatt-hours) is similar, but the overall system costs and the maximum hours of outage experienced by any bus on the network are reduced.

4. The Regional Energy Deployment System (ReEDS) model is a bottom-up electric sector capacity expansion model for the contiguous United States that finds the leastcost construction and operation of generation, storage, and transmission assets through 2050. Under this study, ReEDS was modified to represent forced outage rates on the transmission system. Together with existing model capabilities, this preliminary resilience analysis involved five model constructs that were used to analyze ways to plan for resilience, based on the attribute-based metric of redundancy. Across the full suite of scenarios explored, initial results indicate that resiliency concerns can influence the optimal investment portfolio in different ways, depending on whether you are concerned about operating reserves, resource adequacy at peak loads, more-frequent generator outages, or more transmission outages.

5. The Renewable Energy Optimization (REopt) is a techno-economic decision support model used to optimize energy systems for buildings, campuses, communities, and microgrids. Based on research completed under this study, the tool can now incorporate the avoided cost of a power interruption into the lifecycle cost calculation for backup power systems. Initial results indicate that accounting for the benefits associated with surviving all or part of a grid outage could change the optimal design of a backup power system. In particular, for scenarios that incorporate a "value 
of resilience," the cost-optimal backup power system has increased PV capacity, energy storage duration, and net present value.

Beyond these initially observed outcomes based on preliminary analysis efforts, each modeling team also identified how future research could improve the ability to explore energy resilience in more detail. Moreover, common findings from across our preliminary resilience analyses include:

1. There is no one-size-fits-all metric, nor should one metric be deemed appropriate for implementation in all systems modeling. A multilayered metric system will be needed for resilience work and would be helpful for industry discussion and analysis at many scales.

2. Our current understanding of what customers are willing to pay to avoid longduration power interruptions is highly limited, and it could benefit from an improved understanding of (a) the duration-dependence of customer damages, (b) the influence of sectoral interdependencies, and (c) the relationship between impacts and consequences (e.g., degraded health, safety, and economic activity). There is significant uncertainty about whether these factors can be rigorously quantified.

3. Accurately quantifying how a given resilience investment could lead to performance improvements (and, in turn, value) requires a more fundamental understanding of the relationship among a threat, its impacts, and the resulting consequences. An important area for future research is the development of methodologies for endogenously representing probabilities and a time-dependence for response and recovery activities in energy models.

4. An alternative approach to modifying existing tools to enable them to effectively quantify and estimate the value of potential resilience investments would be to develop a new model specifically for energy sector resilience analysis. However, there are many challenges with such an approach.

In summary, the research presented in this report was motivated by a growing need among energy industry stakeholders to evaluate the resilience of their systems to a variety of threats. In general, previous frameworks have outlined the steps needed to evaluate resilience, which can be summarized through linkages among a variety of research components. A perfect resilience analysis would involve detailed approaches for each individual component of the analysis. However, in an effort to avoid letting "great being the enemy of good," it is often valuable to make simplifying assumptions for certain components of resilience analysis, while approaching others with a higher level of fidelity and granularity.

Within the research community and energy industry, discussions often center on the need for detailed approaches to resilience metrics. However, such requests may only get at part of the ultimate need, as the utility of a metric depends strongly on the ability to evaluate it in a sophisticated and rigorous manner. In this study, we chose to approach resilience analysis by implementing simplified power interruption scenarios and resilience metrics in highly sophisticated simulation and optimization tools. To do so, we modified model inputs, constraints, and/or objective functions to capture the benefits associated with improved resilience, from a variety of stakeholder perspectives. Additionally, across the full suite of models, we quantified resilience in energy models designed to represent generation, transmission, capacity expansion, distributed energy resources, and energy end use. This research demonstrates the value associated with tradeoffs, which help ensure resilience analyses remain tractable for a diverse set of stakeholders. 


\section{Table of Contents}

Executive Summary .........................................................................................................................................

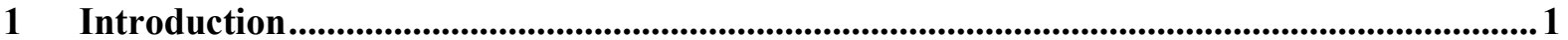

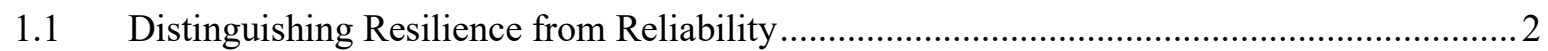

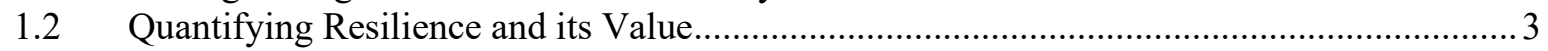

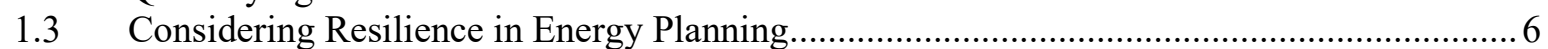

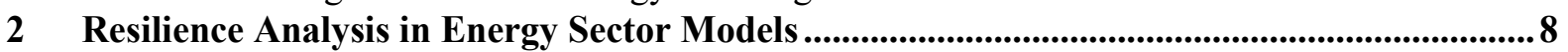

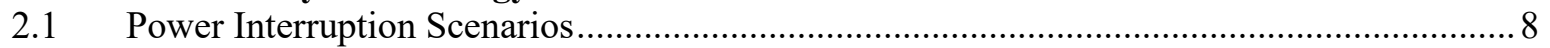

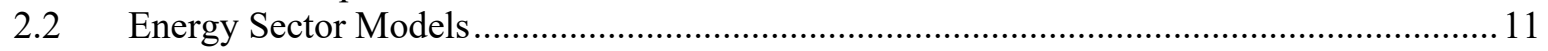

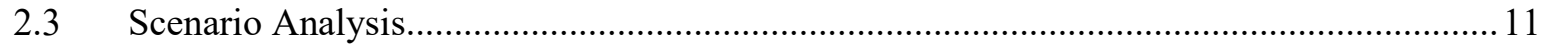

3 Adapting Simulation Models for Resilience Analysis ...................................................................14

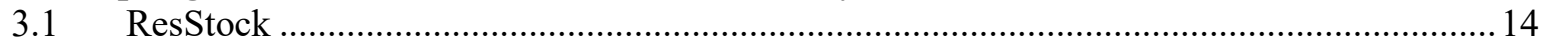

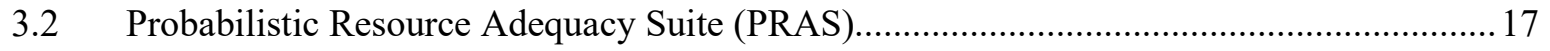

4 Adapting Least-Cost Optimization Models for Resilience Analysis.........................................20

4.1 Scalable Integrated Infrastructure Planning: Power Systems Toolkit (SIIP::Power)............20

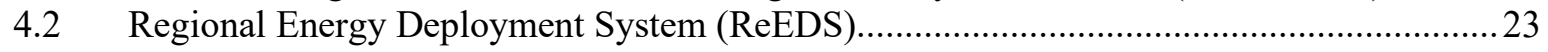

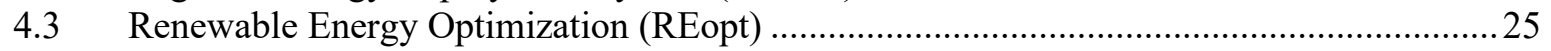

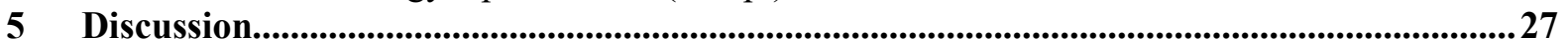

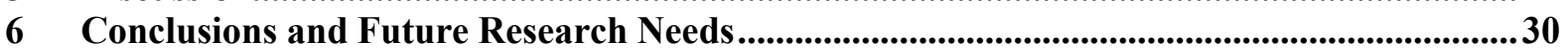

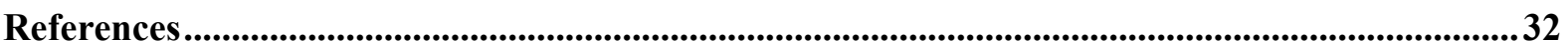

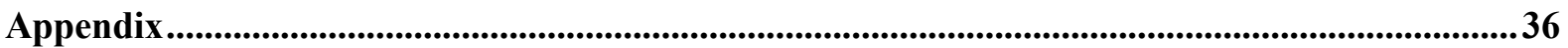




\section{List of Figures}

Figure 1. Internal temperature trajectories (left) and distribution of minimum indoor temperatures (right) for buildings in Buffalo, New York, during a power interruption resulting from a hypothetical 12-hour ice storm, as modeled in ResStock

Figure 2. Internal temperature trajectories for buildings in Chicago, Illinois, during a power interruption resulting from a heat wave, as modeled in ResStock

Figure 3. Expected unserved energy across natural gas disruption scenarios with varying levels of energy storage capacity, as modeled in PRAS.

Figure 4. Under degraded conditions, considering a duration-dependent value of lost load resulted in a modified system dispatch, which reduced outage duration at each bus and overall system costs, as modeled in the production cost model framework in SIIP::Power..

Figure 5. Accounting for the value obtained by mitigating the power interruption experienced by a facility or campus resulted in a cost-optimal backup power system that is larger and incorporates longer-duration storage, as modeled in REopt. ...........................................2 26

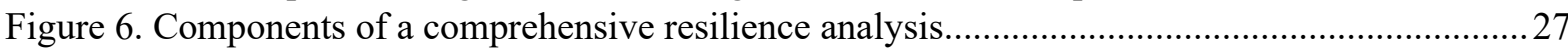

Figure A-1. Sample SIIP::Power results, indicating that the cost of lost load varies with the duration of the outage

\section{List of Tables}

Table 1. Qualitative Comparison of the Attributes of Reliability and Resilience-Testing Events .........2

Table 2. Performance-Based, System-Level Metrics for Reliability and Resilience, Classified by

Perspective and Type of Consequence

Table 3. Example Past Events for Representative Power Interruption Scenarios, Defined by

Preparation Time and Power Interruption Duration

Table 4. NREL Tools in Which Preliminary Resilience Analyses Were Performed............................ 12

Table 5. Model Constructs Used to Analyze Resilience Planning in v2018 ReEDS...........................24

Table 6. Summary of Preliminary Resilience Analyses in Existing NREL Tools................................28 


\section{Introduction}

Within the context of energy systems, definitions of resilience encompass holistic concepts that emphasize preparing for, absorbing, adapting to, and recovering from interruptions in energy supply (White House 2013; DHS 2013; Hotchkiss and Dane 2019; Watson et al. 2014; Stankovic and Tomsovic 2018), which are often characterized by likelihood and impact. ${ }^{1}$ In this study, we refrain from suggesting our own definition for the term resilience; instead, we focus on the characteristics of resilience-testing events that are most important for informing resilience planning and investment decisions. For example, disruptions that test the resilience of a system or community often result in large-scale consequences, which extend over multiple sectors, service types, and timescales.

Recent research has focused on understanding the resilience of the electricity sector to a core set of disruptions, which reflects (1) the economy's increased dependence on electricity, (2) multiple emerging threats to the system (e.g., severe weather, aging infrastructure, cyberattacks, and physical attacks), and (3) the rapid evolution of the electricity system in recent decades (National Academies of Sciences, Engineering, and Medicine 2017). The electricity sector is arguably more advanced in its consideration and assessment of resilience than other critical infrastructure sectors (e.g., water, oil and gas, or telecommunications; Willis and Loa 2015), but it is also more complex, exposed, and vulnerable to disruptions than many of those sectors. Moreover, there are interdependencies between infrastructure sectors to consider (DHS and DOE 2015; Judson 2013; EIS Council 2016), such as the reliance of water treatment and pumps on electricity supplied from the grid and the dependence of hydropower and thermal generators on available water supply.

Power system modelers and operators have been challenged by resilience, including by how to measure the concept and how to apply metrics (Rickerson, Gillis, and Bulkeley 2019). A specific challenge is that while many metrics have been proposed, the implementation, testing, and validation of those metrics has been limited. In part, resilience metrics (in general) have only been validated to a limited extent because of the complexities associated with resilience-testing events, whose consequences depend on the timing, nature, magnitude, impacts, and extent of the realized threat. Moreover, individual metrics are only exercised sporadically because resilience analyses target only the most appropriate metric, which depends on a given stakeholder's goals and perspectives. Beyond the validation of resilience metrics themselves, another prominent challenge lies in how resilience can be quantified, valued, and monetized, as well as how the value of resilience can be integrated into investment or operational decisions.

In general, a resilience metric is a measurable quantity that can inform an entity's broader risk management strategy through the quantification of a system or asset's resilience under a range of natural hazards, intentional threats, and mitigation strategies. While many resilience metrics have been developed (Willis and Loa 2015; GMLC 2017) — primarily from the perspective of the electric utility — most proposed metrics are immature (Willis and Loa 2015), and none is widely agreed upon (National Academies of Sciences, Engineering, and Medicine 2017; Keogh and Cody 2013; Willis and Loa 2015; Vugrin, Castillo, and SilvaMonroy; DOE 2016; Kintner-Meyer et al. 2016).

\footnotetext{
${ }^{1}$ Select examples of power interruption characteristics include low- or high-probability; low- or highconsequence; small- or large-scale; and short- or long-duration events.
} 


\subsection{Distinguishing Resilience from Reliability}

Within the resilience metrics literature, there is agreement on the need for distinct metrics (or characteristics) that go beyond those established for the related concept of electricity system reliability (Table 1). Reliability is defined as the ability to "maintain power delivery to customers in the face of routine uncertainty in operating conditions" (Kintner-Meyer et al. 2016), and it therefore reflects the inherent uncertainty associated with fluctuating load and generation, fuel availability, and outages of assets from different causes. Specific data, metrics, and valuation methods for electricity reliability are mature and widely adopted (GMLC 2017), and they all help inform the mandatory and enforceable reliability standards that are (a) developed by the North American Electricity Reliability Council and (b) reviewed and approved by the Federal Energy Regulatory Commission. Reliability is often considered in integrated resource and transmission planning processes and by regulators and markets (Kintner-Meyer et al. 2016).

Table 1. Qualitative Comparison of the Attributes of Reliability and Resilience-Testing Events

\begin{tabular}{|c|c|c|}
\hline Attribute & Resilience & Reliability \\
\hline $\begin{array}{l}\text { Event } \\
\text { Characteristics }\end{array}$ & $\begin{array}{l}\text { Low-probability, high-consequence, } \\
\text { events that represent black-sky } \\
\text { operating conditions and apply stress } \\
\text { to a system over a large-scale }\end{array}$ & $\begin{array}{l}\text { Uncertainty associated with } \\
\text { fluctuating load and generation, fuel } \\
\text { availability, and outage of assets } \\
\text { under normal operating conditions }\end{array}$ \\
\hline Outage Duration & Days to months & Seconds to hours \\
\hline Spatial Extent & $\begin{array}{l}\text { Large geographic region (e.g., states, } \\
\text { regions, or islands) }\end{array}$ & $\begin{array}{l}\text { Concentrated area (e.g., one facility, } \\
\text { campus, or neighborhood) }\end{array}$ \\
\hline Economic Losses & $\begin{array}{l}\text { Losses arising from both lost load and } \\
\text { cascading impacts to the economy }{ }^{a}\end{array}$ & $\begin{array}{l}\text { Losses largely limited to unserved } \\
\text { load for a subset of customers }\end{array}$ \\
\hline Assets Impacted & $\mathrm{N}-\mathrm{k}^{\mathrm{c}}$ & $\mathrm{N}-1, \mathrm{~N}-1-1$ \\
\hline State of Metrics & $\begin{array}{l}\text { Many immature metrics proposed; } \\
\text { none universally adopted }\end{array}$ & $\begin{array}{l}\text { Mature, well-defined, reported } \\
\text { metrics for the bulk power system } \\
\text { (e.g., loss of load expectation, } \\
\text { expected unserved energy) and } \\
\text { electricity distribution system (e.g., } \\
\text { SAIDI, SAIFI, and CAIDI) }\end{array}$ \\
\hline $\begin{array}{l}\text { Example Entities } \\
\text { Responsible for } \\
\text { Standards }\end{array}$ & None & $\begin{array}{l}\text { North American Electricity Reliability } \\
\text { Council, Federal Energy Regulatory } \\
\text { Commission, Public Utility } \\
\text { Commissions, Institute of Electrical } \\
\text { and Electronics Engineers }\end{array}$ \\
\hline Relevant Data & $\begin{array}{l}\text { Forward-looking modeling and } \\
\text { simulations, with some insights from } \\
\text { infrequent historical events }\end{array}$ & $\begin{array}{l}\text { Aggregation of historical records for } \\
\text { small-scale events over a given } \\
\text { period (e.g., one year) }\end{array}$ \\
\hline
\end{tabular}

a Select examples of cascading impacts include business losses, community economic failures, and degraded water or natural gas delivery to customers as a result of a power.

b Losses associated with dropped load reflect interruptions in services or operations for a limited time

c An N-k contingency involves the near-simultaneous failure of a set of $k$ critical components. Beyond resulting in a maximized power interruption, a key challenge in analyzing $\mathrm{N}-\mathrm{k}$ contingencies lies in identifying which of the possible combinations of component failures are both likely and impactful.

d For acronym definitions, see Table 2 (page 5). 
The distinction between reliability and resilience is particularly important for system planning, cost recovery, and utility regulation. Utilities seeking to identify and invest in resilience solutions must be able to identify measures that either are unique to resilience or provide both resilience and reliability benefits. To recover capital costs for these types of investments, regulated utilities must be able to justify the additional costs within the context of system benefits (i.e., resilience improvements) for all customers. Reliability metrics and assessment methodologies can provide some helpful insights, but they likely undervalue the benefits associated with resilience improvements (Stockton 2014). Moreover, a significant fraction of utilities exclude outages caused by major events ${ }^{2}$ when calculating their performance on reliability metrics (Eto et al. 2012; Keogh and Cody 2013; National Academies of Sciences, Engineering, and Medicine 2017), because the nature of costs from major events are different from those from minor events. ${ }^{3}$ Because major events are most relevant for informing resilience investments, reliability metrics and assessments are likely insufficient for resilience cost-benefit analyses. In addition, the benefits of power sector resilience may expand within given timescales.

Despite their important differences, reliability and resilience often overlap as concepts. Customers value both, and there are likely synergies between their mitigation approaches. In some cases, a measure can improve both the reliability and the resilience of a system (e.g., the relocation of critical equipment to higher elevations or less flood-prone locations). Therefore, considering them separately would likely result in suboptimal solutions, and regulators must be careful to avoid approving cost recovery for separate reliability and resilience investments that provide the same benefits. Co-consideration of reliability and resilience measures will help identify potential tradeoffs between reliability and resilience measures. For example, reinforced concrete poles could improve reliability through resistance to forest fires and wind damage, but they could reduce resilience (in terms of recovery type options after an event), as damaged concrete poles often take longer to replace (Watson et al. 2014; National Academies of Sciences, Engineering, and Medicine 2017; Keogh and Cody 2013).

\subsection{Quantifying Resilience and its Value}

The literature is focused on quantifying resilience, which requires determining both (1) the quantity (or magnitude) of resilience needed and (2) its value to end users, communities, and/or governments. Universally agreed upon metrics and values for resilience are currently lacking, primarily because each quantity depends strongly on circumstances, goals, and perspectives. While electricity customers will experience similar impacts (i.e., loss of service) during multiple types of disruptive events, the specific impacts on the electricity system itself will vary based on the scale and duration of the power interruption; for example, hurricanes, cyberattacks, and long-term drought have different characteristics, consequences, associated scales, and repair and recovery costs and times.

\footnotetext{
${ }^{2}$ According to the analysis that revealed this statistic, major events are "extraordinary power interruptions and are defined by a variety of criteria to differentiate them from routine power interruptions. There are several different definitions for major events. (See Eto and LaCommare 2008, Endnote Error! Bookmark not defined.). IEEE Standard 1366-2003 is a voluntary industry standard that articulates a consistent set of definitions and procedures for measuring and reporting distribution reliability information, including a heuristically-derived and statistically- based definition of major events." (Eto et al. 2012)

${ }^{3}$ Estimates in the corresponding references range from $25 \%$ to $50 \%$ of regulated utilities and up to two-thirds of public power utilities, based on responses to surveys regarding the reporting of reliability metrics.
} 
Resilience metrics must reflect the underlying resilience goals, the diverse array of which depends on perspective and encompasses the broad definition of resilience. The primary resilience goal of an electric utility may focus on rapid recovery of the system as a whole after an extreme event. However, community leaders may focus on providing essential services, as well as the unforeseen consequences of a large-scale, long-duration event, such as the interdependencies of electricity service with other essential services (e.g., water, natural gas, and telecommunications). In turn, the corresponding metrics associated with these goals are related but inherently different (Table 2).

Several approaches have been developed in which metrics are developed and evaluated in order to quantify resilience, including the Resilience Analysis Process (Vugrin, Castillo, and Silva-Monroy 2017) and a matrix format for quantifying energy resilience (Roege et al. 2014). Resilience metrics can be categorized as "attribute-based" or "performance-based." Attribute-based resilience are "based on system characteristics and typically include categories of system properties that are generally accepted as being beneficial to resilience" (Watson et al. 2014); as a result, they tend to be implemented through qualitative measurements and processes that include systematic review. By contrast, performance-based resilience metrics "measure how well the system delivers on its intended purpose during and after the threat" (Watson et al. 2014); they tend to be data-driven, and they have been implemented for both postmortem and prescriptive analyses.

For quantitative analysis, it is preferable to use performance-based metrics that consider both likelihood and consequence of a given event and its corresponding consequences, as well as temporal evolution of an event. The performance of the system is crucial to electric resilience, so the metrics highlighted in Table 2 are those that can be quantitatively evaluated through infrastructure performance (e.g., using energy sector models) (Vugrin, Castillo, and Silva-Monroy 2017).

Quantitative, performance-based metrics and modeling are inherently forward-looking ${ }^{4}$ and are particularly important for informing planning and investment efforts related to resilience solutions, as well as potential response and recovery activities (National Academies of Sciences, Engineering, and Medicine 2017). However, detailed quantitative resilience analysis is not always possible, because of data or analytical resource limitations. As a result, "attribute-based" metrics have been developed to reflect more-qualitative characteristics that describe what makes a system resilient (e.g., robust, adaptive, and flexible) (GMLC 2017).

The most mature performance-based metrics have largely been developed for use at the utility or system levels (GMLC 2017). The sheer volume of individual resilience metrics that have been proposed (on the order of many tens of metrics) makes it difficult to summarize them, but categorizing resilience metrics helps simplify the discussion. The Grid Modernization Laboratory Consortium (GMLC 2017) summarized performance-based resilience metrics as falling into the following direct consequence categories: electrical service, critical electrical service, restoration, and monetary (Table 2). The distinction between the first two categories lies in the customers considered (i.e., all customers versus critical customers, such as those that provide emergency services), while the final two categories focus more on the timing and cost of recovery, largely from the utility perspective.

\footnotetext{
${ }^{4}$ Given the infrequent nature of long-duration outages, forward-looking (or leading) metrics are likely more relevant than lagging metrics. However, it is worth noting that both lagging and leading metrics are typically used for reliability events, given that historical data for reliability events are widely collected and available.
} 
Table 2. Performance-Based, System-Level Metrics for Reliability and Resilience, Classified by Perspective and Type of Consequence

\begin{tabular}{|c|c|c|c|}
\hline & Reliability Metric [Units] & Resilience Metric [Units] & $\begin{array}{l}\text { Perspective } \\
\text { (Example of } \\
\text { Organization Type) }\end{array}$ \\
\hline \multirow{6}{*}{ 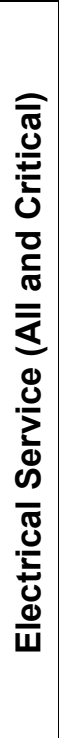 } & $\begin{array}{l}\text { Customer minutes interrupted } \\
\text { (CMI) [mins.] }\end{array}$ & $\begin{array}{l}\text { Customer-hours of outages [hrs.] or } \\
\text { load not served [kilowatt-hours, or kWh] }\end{array}$ & Utility \\
\hline & $\begin{array}{l}\text { Customers interrupted [number } \\
\text { of customers] }\end{array}$ & $\begin{array}{l}\text { Average number (or percentage) of } \\
\text { customers experiencing an outage }\end{array}$ & Utility \\
\hline & $\begin{array}{l}\text { System average interruption } \\
\text { frequency index (SAIFI) }\end{array}$ & $\begin{array}{l}\text { Critical customer-hours of outages [hrs.] } \\
\text { or load not served [kWh] }\end{array}$ & $\begin{array}{l}\text { Community leaders, } \\
\text { Utility }\end{array}$ \\
\hline & $\begin{array}{l}\text { System average interruption } \\
\text { duration index (SAIDI) } \\
\text { [mins./customer] }\end{array}$ & $\begin{array}{l}\text { Average number (or \%) of critical } \\
\text { customers experiencing an outage }\end{array}$ & $\begin{array}{l}\text { Community leaders, } \\
\text { Utility }\end{array}$ \\
\hline & $\begin{array}{l}\text { Customer average interruption } \\
\text { duration index (CAIDI) } \\
\text { [hrs./customer] }\end{array}$ & $\begin{array}{l}\text { Critical services (e.g., hospitals, fire } \\
\text { stations, and police stations) without } \\
\text { power }\end{array}$ & Community leaders \\
\hline & $\begin{array}{l}\text { Customers experiencing } \\
\text { multiple interruptions (CEMI) }\end{array}$ & $\begin{array}{l}\text { Critical services without power for more } \\
\text { than } N \text { hours (e.g., } N>\text { hours of backup } \\
\text { fuel requirement) }\end{array}$ & Community leaders \\
\hline \multirow{7}{*}{ 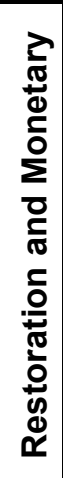 } & $\begin{array}{l}\text { System average restoration } \\
\text { index (SARI) [min] }\end{array}$ & Time to recovery [hrs.] & Utility, Insurance \\
\hline & \multicolumn{2}{|c|}{ Loss of utility revenue $[\$]$} & Utility, Insurance \\
\hline & \multicolumn{2}{|c|}{ Cost of grid damages $[\$]$} & Utility, Insurance \\
\hline & \multicolumn{2}{|c|}{ Cost of recovery $[\$]$} & Utility, Insurance \\
\hline & \multicolumn{2}{|c|}{ Avoided outage cost $[\$]$} & Utility, Insurance \\
\hline & \multicolumn{2}{|c|}{ Loss of assets and perishables [\$] } & Insurance \\
\hline & \multicolumn{2}{|c|}{ Business interruption costs $[\$]$} & Insurance \\
\hline
\end{tabular}

Thin vertical lines separate related metrics for reliability and resilience, and thick lines indicate separate metrics that fall under the same consequence category (far left column). Resilience metrics tend to be leading (i.e., forward-looking) in nature and can be focused on critical customers; reliability metrics can also be forward-looking, but they are often based on historical data that represent averages across multiple events and a given system. The table provides a qualitative comparison of select metrics for resilience and reliability events, but it is not meant to be comprehensive.

For all categories, it is important to consider the dimensions across which the metric is evaluated and reported. For example, each of the electrical service resilience metrics in Table 2 could be evaluated as a final integrated value that summarizes system performance throughout the event (i.e., during the disturbance), in the wake of the disturbance, and throughout the restoration process. However, depending on your perspective and goals, the time-dependence of a given metric over the course of an event could be of interest (Panteli et al. 2017). For example, a utility might want to know the sequence of events, such as how rapidly the service level to all customers (or critical customers) was reduced, the minimum level of electrical service that was provided (and the duration over which that minimum level 
occurred), how quickly service was restored, or the time evolution of lost revenue. Or, a city might be interested to know the time evolution over which critical services lost power, which would provide insights as to whether the loss of critical services was due to backup generator failures or an event duration that exceeded the ability for backup power to maintain power.

A final and challenging step is translating impacts to consequences regarding societal welfare. For example, a long-duration power interruption would likely have direct effects on the health and safety of a community, due to the loss of critical community services (e.g., hospitals, fire stations, or police stations). However, many factors inform this relationship. Accurately assessing the impacts of the outage itself also requires comparison against the relevant "baseline" health and safety of a community, which depends on highly localized demographic and intangible factors. A long-duration power interruption could also indirectly effect (or threaten) the health and safety of a community, such as through degraded national security (e.g., due to the loss of critical infrastructures or long-duration outages at military bases). Finally, a very important step lies in translating the consequences of a long-duration power interruption to the loss of human life, the "value" of which is highly controversial (Viscusi and Aldy 2003).

\subsection{Considering Resilience in Energy Planning}

Some insights into the costs of potential resilience measures have been reported by utilities engaged in resilience planning in the wake (or anticipation) of emerging threats. For example, following Hurricane Sandy in 2012, the Edison Electric Institute released a report summarizing "best practices with regards to hardening the distribution infrastructure and creating a more resilient system" (EEI 2014). The report serves as a useful resource for utilities by providing a menu of options for hardening and resilience measures at the distribution level, as well as their relative cost impacts, cost recovery mechanisms, and relevant state programs. Common mitigation measures include "undergrounding" of power lines, vegetation management, higher design and construction standards, and smart grid, microgrid, and advanced technologies, as well as planning and operational measures that improve recovery times (e.g., an increased labor force, standby equipment, and restoration materials). A similar summary that covered a wider array of threats and solutions provides a comparable list of common mitigation measures, but it placed greater emphasis on the growing importance of advanced meters, smart-grid technologies, cybersecurity measures, and probabilistic risk models (Finster, Phillips, Wallace 2016).

For regulated utilities, investments are subject to the approval of the regulators who are responsible for evaluating the economics of such measures. Interviews with public utility commission staff found that requests for cost recovery or investments in resilience are typically included in general rate case proceedings, although little or no distinction is made between reliability and resilience. Moreover, while the cost of a given resilience measure is well understood (e.g., the costs of labor and materials to "underground" specific power lines), the resulting benefits are more difficult to assess, particularly because of a lack of supporting data (LaCommare, Larsen, and Eto 2017). ${ }^{5}$ The types of data that would support the benefits associated with resilience measures are difficult to collect because of the time and types of events needed to demonstrate the value of resilience investments (e.g., 1,000-year flood events happen so infrequently that the benefits of mitigation measures associated with those events are difficult to quantify in a realistic time frame). In addition, demonstrating that a

\footnotetext{
${ }^{5}$ Two primary reasons for this are the infrequent nature of this type of event (some of which have never occurred before) and the lack of a universal methodology for quantifying the cost of a given interruption (e.g., to residential or government customers).
} 
local investment will provide benefits to the broader customer base is often challenging (Rickerson, Gillis, and Bulkeley 2019). These findings represent an important challenge for resilience investments, as the use of reliability metrics alone may be insufficient for guiding investments in mitigation strategies for more costly and higher-impact disruptive events

(National Academies of Sciences, Engineering, and Medicine 2017; Keogh and Cody 2013). 


\section{Resilience Analysis in Energy Sector Models}

Recognizing that implementing, testing, and validating resilience metrics are challenges that need to be addressed, we dedicated staff and time to researching how to effectively integrate resilience considerations into energy sector models and tools. The overarching goal of this effort was to evaluate the data needs, methodologies, and outcomes - including consequences and/or changes in investment or operational decisions due to avoided consequences - based on resilience analysis in a range of existing tools. This section provides a brief overview of the underlying approach to achieving this goal, which includes defining generalized power interruption scenarios, identifying an appropriate range of tools, and performing and interpreting results from preliminary resilience scenario analyses.

\subsection{Power Interruption Scenarios}

The first step in our research effort was the development of power interruption scenarios, which were intended to help establish a framework for simulating real-world grid outages and their impacts on system components. In this case, the term "threat" refers to something that could negatively impact some part of the energy system, which we define them based on variations across two dimensions: (1) whether system operators have time to prepare and (2) the duration of the associated power interruption. These two dimensions were chosen to capture both the variation in the types of threats on a given system, as well as variation in the severity of events types.

The resulting suite of power interruption scenarios were defined by the:

- Forecast availability, in terms of preparation time before an event occurs: 0 , less than 12 , and greater than 12 hours

- Duration of the power interruption: less than 12 or greater than 12 hours.

These thresholds were chosen primarily based on existing model parameterizations, which include both day-ahead scheduling and real-time operations. In addition, they were developed with potential bulk power system performance impacts in mind, which can be classified as one of the following:

- The bulk power system can serve all load but may need re-dispatch, commitment, or configuration.

- Bulk power system generation capacity is sufficient, but the transmission network is compromised.

- Both generation and transmission are compromised at the bulk power system level.

While we did not define the power interruption scenarios based on a specific event type, Table 3 offers additional intuition by providing examples of causes that could lead to power interruptions with similar levels of advanced notice (i.e., time for preparation) and duration. As outlined in the Federal Emergency Management Agency's Critical Infrastructure Protection Program (DHS 2018), ${ }^{6}$ the three widely acknowledged categories for disruptive events to infrastructure performance are:

- Human-caused disruptions could be related to a lack of maintenance, insufficient vegetation management programs, or adversarial acts, for example.

\footnotetext{
6 "Lesson Summary_Lesson 4: Managing Risk, FEMA, https://emilms.fema.gov/IS0921a/CIPP0104summary.htm.
} 
- Natural hazards typically include weather related events (e.g., tornadoes, hurricanes, floods, storm surge, flooding, and ice storms) and earthquakes, among other hazards.

- Technological failures could include equipment failures, or system malfunction that are due to poor design or overloaded lines, for example.

These three categories are reflected in the examples provided in Table 3 (page 10). It is important to note that a power interruption's duration cannot be generalized across all instances of a given event type. For example, one cannot know a priori whether the duration of a power interruption associated with a hurricane would be longer or shorter than that of a tornado; in each case, the duration will depend on the strength of the event, as well as on the magnitude and extent of its impacts (e.g., damage to critical grid assets). Similarly, a simple relationship does not currently exist between an event type and the recovery time associated with it, since this will depend on characteristics of the event itself, as well as on impacts on other critical infrastructure sectors (e.g., the inundation of roads that are needed for recovery effort). Instead, a power interruption's duration is primarily a function of how a system performs against, and how quickly it can recover from an event.

By contrast, the degree of advanced notice depends on the forecasting characteristics of a given threat type. Human-caused and technological threats typically occur with little or no warning, while natural threats inherently have different forecast availabilities, which inform both when the event will occur and when crews might be able to commence recovery activities. For example, earthquakes typically occur with little or no warning, whereas advanced notice before a wildfire, tsunami, regional storm, or tornado could range from minutes to hours (depending on proximity to the origination of the event). Other natural events, such as hurricanes or volcanic activity, can be reasonably forecasted many hours or days before the event. ${ }^{7}$

The general scenario definitions and examples provided in Table 3 are for the types of scenarios that energy models could consider and the dimensions that could be important to represent endogenously; however, additional research is needed to enable such representations. For example, data limitations inhibit the endogenous representation of response and recovery activities, which are a necessary component for informing the duration of a given power interruption. Recovery timelines may be a function of advanced notice, type, and timing of the threat of interest; available resources; and dependency (or interdependency) with other critical infrastructures. This limitation primarily represents a need for data to inform such a relationship, as the improved understanding could be translated into energy decision models in a variety of ways.

Another important research area lies in the improved forecasting of extreme events, particularly for renewable energy resources. In general, increased advanced notice can improve the bulk power system operators' ability to cost-effectively plan and prepare for a major event, thus reducing overall recovery times. In addition, considering spatial temperature forecasts and prior precipitation data can improve predictions for the availability of renewable generation resources during extreme events, thus removing surprise failures on the system.

\footnotetext{
${ }^{7}$ More-chronic natural stressors on the energy system (e.g., drought) can have forecast availabilities of weeks to months or years; however, these stressors are often treated separately, as they do not represent acute threats to the energy system.
} 
Table 3. Example Past Events for Representative Power Interruption Scenarios, Defined by Preparation Time and Power Interruption Duration

Power Interruption Duration

\begin{tabular}{|c|c|c|}
\hline & $<12$ Hours & $>12$ Hours \\
\hline None & $\begin{array}{l}\text { In December 2015, three electric grid control centers in eastern } \\
\text { Ukraine were the subject of a cyberattack. Though the event was } \\
\text { initially facilitated by spear-phishing tactics that were employed } \\
\text { months in advance, the attackers ultimately shut down the grid } \\
\text { without any warning. While the duration of the power interruption } \\
\text { was relatively short (on the order of hours), the attack had severe } \\
\text { implications for the long-term operational levels of the system. }\end{array}$ & $\begin{array}{l}\text { On July } 27,2017 \text { a construction crew working on a replacement } \\
\text { bridge in the Outer Banks of North Carolina severed a power cable; } \\
\text { this caused an eight-day blackout during peak tourist season on the } \\
\text { Outer Banks, affecting more than } 7,000 \text { people. }\end{array}$ \\
\hline $\begin{array}{l}<12 \\
\text { Hours }\end{array}$ & $\begin{array}{l}\text { On June } 7,2018 \text { a tornado was reported } 8 \text { miles outside Laramie, } \\
\text { Wyoming, and it stayed on the ground for } 45 \text { minutes. The storm } \\
\text { disrupted sections of the electric grid and nearby towns were } \\
\text { without power for } 4 \text { hours due to reports phoned in and system } \\
\text { operators being able to route power and de-energize lines. }\end{array}$ & $\begin{array}{l}\text { In January 1998, a severe ice storm occurred over Eastern Canada } \\
\text { and New England. "At its peak, more than } 5.2 \text { million customers in } \\
\text { the interconnected areas of Eastern Canada, New York, and New } \\
\text { England were without power. Three weeks after the storm, hundreds } \\
\text { of thousands of customers still had no power, with some customers } \\
\text { not getting power restored until more than } 1 \text { month later (RMS, } \\
\text { 2008)." (NAS 2017) }\end{array}$ \\
\hline $\begin{array}{l}>12 \\
\text { Hours }\end{array}$ & $\begin{array}{l}\text { In } 2019 \text {, Hurricane Dorian neared the Florida coastline after } \\
\text { devastating the Bahamas. Though the hurricane remained off the } \\
\text { coast of Florida, it caused power outages in the state by blowing } \\
\text { downed trees, vegetation, and debris into power lines. Given the } \\
\text { significant advanced notice afforded to Florida utilities, power was } \\
\text { restored quickly, with Florida Power and Light reporting that the } \\
\text { average customer's power was restored in approximately one } \\
\text { hour. The utility cited their previous smart grid technology and } \\
\text { system hardening investments as key to avoiding outages and } \\
\text { reducing restoration times for the } 160,000 \text { customers that did } \\
\text { experience outages as a result of the storm (FPL 2019). }\end{array}$ & $\begin{array}{l}\text { In } 2017 \text {, two Category } 5 \text { hurricanes, Irma and Maria, damaged Saint } \\
\text { Croix, Saint John, and Saint Thomas in the U.S. Virgin Islands, as } \\
\text { well as Puerto Rico and other smaller islands. Hurricane Irma hit the } \\
\text { U.S. Virgin Islands on September 6, with the eye passing over St. } \\
\text { Thomas and St. John. On September } 20 \text {, the eye of Hurricane Maria } \\
\text { swept near St. Croix with maximum winds of } 175 \mathrm{mph} \text {. The } \\
\text { destruction the storms left on the islands - about } 90 \% \text { of customers } \\
\text { lacked power in September - was at times overshadowed by the } \\
\text { catastrophic devastation on neighboring Puerto Rico. About half of } \\
\text { Puerto Rico's more than three million people did not have electricity } \\
100 \text { days after Maria cut across the territory. }\end{array}$ \\
\hline
\end{tabular}




\subsection{Energy Sector Models}

For this preliminary resilience analysis effort, we selected a range of models that represent different segments of the energy sector, geographic scales, and modeling approaches. The models we selected (Table 4) span simulations of regional building stocks and campus-level backup power systems, to the bulk power system across the contiguous United States. In addition, we chose tools with very different modeling approaches; in general, the selected models can be categorized as either (1) optimization models for both long-term planning and electricity dispatch (ReEDS, REopt, and SIIP::Power) or (2) detailed simulation models of resource adequacy for electricity supply (PRAS) and building stock performance (ResStock).

The range of metrics that were implemented across the suite of models demonstrates the importance of stakeholder perspectives and model architectures when identifying the most appropriate resilience metric (Table 4). For example, the chosen metric in ResStock-which simulates energy use and thermal performance in the U.S. residential building stock-is intuitively based on the perspective of a building resident. Moreover, PRAS takes the perspective of an energy supplier, who is concerned with the possibility of unserved energy due to resource inadequacy. As a result, the resilience metric that was implemented in PRAS is the expected unserved energy. While this metric is typically used in reliability analysis, we found its application here to be appropriate because it was applied to a power interruption scenario that corresponds to a resilience-testing event (see Section 3.2).

The selection of metrics based on stakeholders' resilience goals may be informed by their available data and/or analytical capabilities. Therefore, another important consideration in selecting resilience metrics lies in the architecture(s) of available energy sector models, which is captured by the range of models included in our preliminary resilience analysis efforts. In particular, in contrast to the models discussed in the previous paragraph, the leastcost optimization models are formulated to minimize system costs, based on a variety of input assumptions and subject to multiple constraints. As a result, the chosen metrics in leastcost optimization more often take the form of a resilience "value," or a measure of the damages incurred as a result of an interruption in electricity supply. The one exception is the chosen metric in ReEDS (Table 4), which is a long-term capacity expansion model. In this case, the modeling team chose to implement and evaluate an attribute-based metric (Section 1.1.2), because of the model's inability to represent localized short-term interruptions on the bulk power system.

\subsection{Scenario Analysis}

The remainder of this report presents results from our preliminary resilience analyses in existing NREL models. Each modeling team considered the proposed suite of power interruption scenarios and identified which ones could be adequately represented within their modeling framework. Among the candidate power interruption scenarios, each modeling team chose one to explore by attempting to understand the necessary methodologies, data, and resulting outcomes that could be evaluated (Table 4). 
Table 4. NREL Tools in Which Preliminary Resilience Analyses Were Performed

\begin{tabular}{|c|c|c|c|c|}
\hline \multicolumn{2}{|c|}{ Features of the Underlying Models } & \multicolumn{3}{|c|}{ Description of Preliminary Resilience Analyses } \\
\hline Name & Description & Analysis Approach & $\begin{array}{l}\text { Power Interruption } \\
\text { Scenario }\end{array}$ & Resilience Metric \\
\hline ResStock & $\begin{array}{l}\text { Physics-based simulation of } \\
\text { the energy use and thermal } \\
\text { performance of the U.S. } \\
\text { residential building stock }\end{array}$ & $\begin{array}{l}\text { Development of methods for } \\
\text { (1) representing a power outage and } \\
\text { (2) measuring thermal resilience, } \\
\text { defined as the ability of a building to } \\
\text { maintain livable indoor temperatures } \\
\text { during loss of electricity or gas supply }\end{array}$ & $\begin{array}{l}\text { Both Short and } \\
\text { Long-Duration } \\
\text { Power Interruptions } \\
\text { with No Preparation } \\
\text { Time }\end{array}$ & $\begin{array}{l}\text { Social consequence measured } \\
\text { via (a) time to unsafe indoor } \\
\text { conditions during adverse } \\
\text { outdoor conditions or (b) } \\
\text { minimum/maximum indoor } \\
\text { temperature }\end{array}$ \\
\hline $\begin{array}{l}\text { Probabilistic } \\
\text { Resource } \\
\text { Adequacy Suite } \\
\text { (PRAS) }\end{array}$ & $\begin{array}{l}\text { Probabilistic simulation of } \\
\text { simplified power system } \\
\text { operations and load shortfalls } \\
\text { under random and/or } \\
\text { exogenously-forced } \\
\text { generation outages on the } \\
\text { bulk power system }\end{array}$ & $\begin{array}{l}\text { Development of a sequential } \\
\text { simulation mode for tracking storage } \\
\text { device state-of-charge, to facilitate } \\
\text { evaluation of a multi-day fuel supply } \\
\text { disruption under differing options for } \\
\text { local energy storage ride-through }\end{array}$ & $\begin{array}{l}\text { Long-Duration } \\
\text { Power Interruption } \\
\text { with No Preparation } \\
\text { Time }\end{array}$ & $\begin{array}{l}\text { System performance measured } \\
\text { via expected unserved energy }\end{array}$ \\
\hline $\begin{array}{l}\text { Scalable Integrated } \\
\text { Infrastructure } \\
\text { Planning Power } \\
\text { Systems Toolkit } \\
\text { (SIIP::Power) }\end{array}$ & $\begin{array}{l}\text { Least-cost optimization of } \\
\text { day-ahead and real-time bulk } \\
\text { power system scheduling } \\
\text { problems, adapted for } \\
\text { resiliency representation }\end{array}$ & $\begin{array}{l}\text { Development of a methodology for } \\
\text { co-optimizing the dispatch of } \\
\text { generation with the avoided power } \\
\text { interruption cost }\end{array}$ & $\begin{array}{l}\text { Long-Duration } \\
\text { Power Interruption } \\
\text { with No Preparation } \\
\text { Time }\end{array}$ & $\begin{array}{l}\text { Economic consequence } \\
\text { measured via location- and } \\
\text { duration-dependent value of lost } \\
\text { load }\end{array}$ \\
\hline $\begin{array}{l}\text { Regional Energy } \\
\text { Deployment } \\
\text { System (ReEDS) }\end{array}$ & $\begin{array}{l}\text { Least-cost optimization for the } \\
\text { development and operation of } \\
\text { generation, storage, and } \\
\text { transmission assets on the } \\
\text { bulk power system across the } \\
\text { contiguous United States }\end{array}$ & $\begin{array}{l}\text { Increasing service requirements, } \\
\text { outage rates for electricity generation } \\
\text { assets, and outage rates for } \\
\text { transmission assets, the latter of } \\
\text { which is a new capability in the } \\
\text { model }\end{array}$ & $\mathrm{N} / \mathrm{A}$ & $\begin{array}{l}\text { Attribute-based metric of } \\
\text { redundancy }\end{array}$ \\
\hline $\begin{array}{l}\text { Renewable Energy } \\
\text { Optimization } \\
\text { (REopt) }\end{array}$ & $\begin{array}{l}\text { Least-cost optimization for the } \\
\text { development and operation of } \\
\text { distributed energy resources } \\
\text { at a facility or campus scale }\end{array}$ & $\begin{array}{l}\text { Development of a methodology for } \\
\text { considering avoided power } \\
\text { interruption costs in investment } \\
\text { decisions related to backup power } \\
\text { systems }\end{array}$ & $\begin{array}{l}\text { Short-Duration } \\
\text { Power Interruption } \\
\text { with No Preparation } \\
\text { Time }\end{array}$ & $\begin{array}{l}\text { Avoided economic consequence } \\
\text { measured via a static "value of } \\
\text { resilience," or the value } \\
\text { associated with mitigating a } \\
\text { power interruption for the end } \\
\text { user }\end{array}$ \\
\hline
\end{tabular}


In the case of the detailed simulation models, the methodology for enabling resilience analysis primarily involved modifications to the scenario definitions, although structural changes were also made in ResStock (see Section 3.1). For the least-cost optimization models, the chosen methodology took the form of modifications to the models' input assumptions, as opposed to fundamental changes to the model architectures. However, an interesting distinction can be made between preliminary resilience analyses that involved (1) modifications to the model constraints (ReEDS) and (2) modifications to the models' objective functions (SIIP::Power and REopt).

The following results represent preliminary efforts, which demonstrate a helpful approach and mindset for incorporating resilience into existing tools and models. Though this research effort was motivated by the need to facilitate resilience analysis, some of these examples may be better classified as evaluating reliability events (e.g., due to their shorter duration; Table 1). This limitation reflects the time and resources dedicated to these preliminary efforts - and not inherent limitations of the models themselves. To expand on this, each subsection in Section 3 and Section 4 includes future development and/or research that would improve our ability to perform resilience analysis, by better representing the impacts of advanced notice, longer-duration power interruptions, and/or response activities. 


\section{Adapting Simulation Models for Resilience Analysis}

This section summarizes the preliminary resilience analysis we performed in ResStock and PRAS. The formulations of these models enable the simulation of system response, given a deterministic threat. For this study, each model was used to explore a single power interruption scenario from Table 3 and evaluate its impact on a resilience metric that corresponds to a native (or slightly modified) output of the model. In other words, resilience did not inform or modify the model's calculation itself; instead, it took the form of providing context for the model results.

\subsection{ResStock}

ResStock is a tool for simulating energy use in housing stocks at national, regional, or local scales. ${ }^{8}$ It combines a database of the energy related characteristics of the housing stock, statistical sampling of the database, and sub-hourly building energy simulations using OpenStudio ${ }^{9}$ and EnergyPlus. ${ }^{10}$ ResStock has been used to evaluate the national potential energy savings from various efficiency upgrades, develop state fact sheets on the most costeffective upgrades, and evaluate upgrades for low income households (Wilson et al. 2017, 2019). To analyze the resilience of residential single-family detached buildings in the contiguous United States, we added to ResStock the ability to simulate power outages and track metrics related to thermal resilience - the ability of a building to maintain livable indoor temperatures during loss of electricity or gas supply.

To capture thermal resilience in ResStock, we added the ability to simulate a power outage and report metrics related to thermal resilience. In particular, we created two OpenStudio measures, which are scripts that make programmatic changes to OpenStudio models. The first of these measures simulated an outage by turning off all electric equipment in the home during the period specified as an outage, as well as fuel-fired heating equipment that requires electricity (e.g., gas furnaces and boilers with circulation pumps). Occupancy related schedules were assumed to be unchanged during an outage period-which is a simplifying assumption that might not hold for long-duration interruptions due to extreme weather events - and residential backup power systems were not represented. The second measure adds outputs for the thermal resilience metrics for the home. The metrics used here for an outage period were primarily concerned with the potential health impacts in terms of the risk of exposure to extreme heat or cold, but such metrics could also be used to evaluate potential damage to building infrastructure, such as freezing pipes.

\section{Reported Thermal Resilience Metrics}

For cold weather scenarios, dry bulb temperature is the main thermal stress factor. For hot weather scenarios, sweating is the primary means of rejecting body heat, which means humidity is a key variable. More than 50 different heat stress indices have been proposed as thermal resilience metrics, but wet-bulb globe temperature (WBGT) is used as the heat stress index for workplace exposure limits by the Occupational Safety and Health Administration (OSHA), the Center for Disease Control and Prevention (CDC), and the International Organization for Standardization (ISO).

\footnotetext{
${ }^{8}$ https://resstock.nrel.gov

9 https://www.openstudio.net

${ }^{10} \mathrm{https}: / /$ energyplus.net
} 
The Leadership in Energy and Environmental Design (LEED) green building rating system includes a pilot credit program designed to evaluate and credit the thermal resilience of a building during a power interruption (Pearson 2015). The pilot credit suggests threshold values below $54^{\circ} \mathrm{F}$ dry bulb during a cold wave and $86^{\circ} \mathrm{F}$ dry bulb with $50 \%$ relative humidity (which is equivalent to $76^{\circ} \mathrm{F}$ WBGT) during a heat wave as thresholds for the "livable" temperature during a power interruption. OSHA suggests a higher workplace exposure limit of $86^{\circ} \mathrm{F}$ for the WBGT.

For this preliminary resilience analysis, we used ResStock to predict indoor conditions and estimate (1) how long it would take the indoor air temperature to go outside the range of livable temperatures and (2) the minimum indoor dry bulb (during a cold wave) and maximum WBGT (during a heat wave) during a power interruption.

\section{Power Interruption Scenarios}

To demonstrate the new capabilities of ResStock, simulations were done for the single-family housing stock for two power interruption scenarios:

1. Heat wave: 8,000 simulations representing the single-family housing stock in and around Chicago, Illinois, in the summer of 2012 (July 6-10)

2. Cold wave: 1,500 simulations representing the single-family housing stock in and around Buffalo, New York, in the winter of 2014 (January 3-7)

These particular scenarios were chosen, as they were part of large heat and cold waves that affected a significant part of the contiguous United States. Moreover, they represent some of the worst-case scenarios for a power interruption from a thermal comfort perspective.

Two different power interruption durations were simulated for each location: a shorter eighthour outage and a longer four-day outage. In Buffalo, the power interruption starts at 9 p.m. due to a hypothetical ice storm, while in Chicago the power interruption starts at noon due to hypothetical distribution system failures caused by the high outdoor air temperatures. The power interruption scenarios used here captured part (but not all) of the heat and cold wave events in each location. These scenarios can be thought of as having no preparation time, as they do not reflect any preheating or precooling that could occur if a customer expected an outage could happen soon.

\section{Scenario Results}

Figure 1 (page 16) presents the results of the preliminary resilience analysis based on a hypothetical ice storm in Buffalo, New York, where the black line indicates the assumed threshold for livable temperatures. The two graphs illustrate the results from the Buffalo ice storm scenario, as modeled in ResStock. The first graph shows the temperature trajectories over the first twelve hours of the power interruption, whereas the second graph represents the distribution of maximum indoor temperatures. The colors show the decade in which the buildings were constructed.

During the cold wave (during which outdoor temperatures go as low as $-20^{\circ} \mathrm{F}$ ), all the homes drop outside the range of livable temperatures within the eight-hour period of the shorter power interruption, with minimum indoor air temperatures significantly below the livable threshold. However, newer homes tend to go longer before falling outside the livable range and have higher minimum indoor air temperatures. Newer homes tend to be more efficient, having more insulation and lower infiltration rates, so vintage serves as a useful proxy for efficiency in this preliminary analysis effort. 


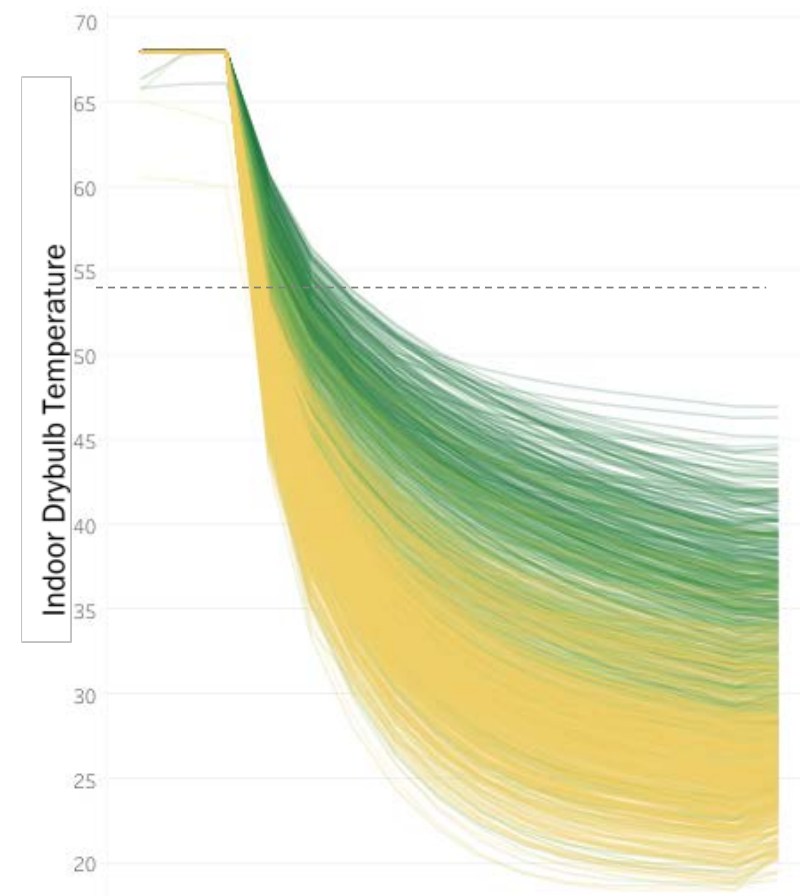

$\operatorname{Jan} 36 \mathrm{PM} \operatorname{Jan} 39 \mathrm{PM} \operatorname{Jan} 412 \mathrm{AM} \operatorname{Jan} 43 \mathrm{AM} \operatorname{Jan} 46 \mathrm{AM} \operatorname{Jan} 49 \mathrm{AM}$

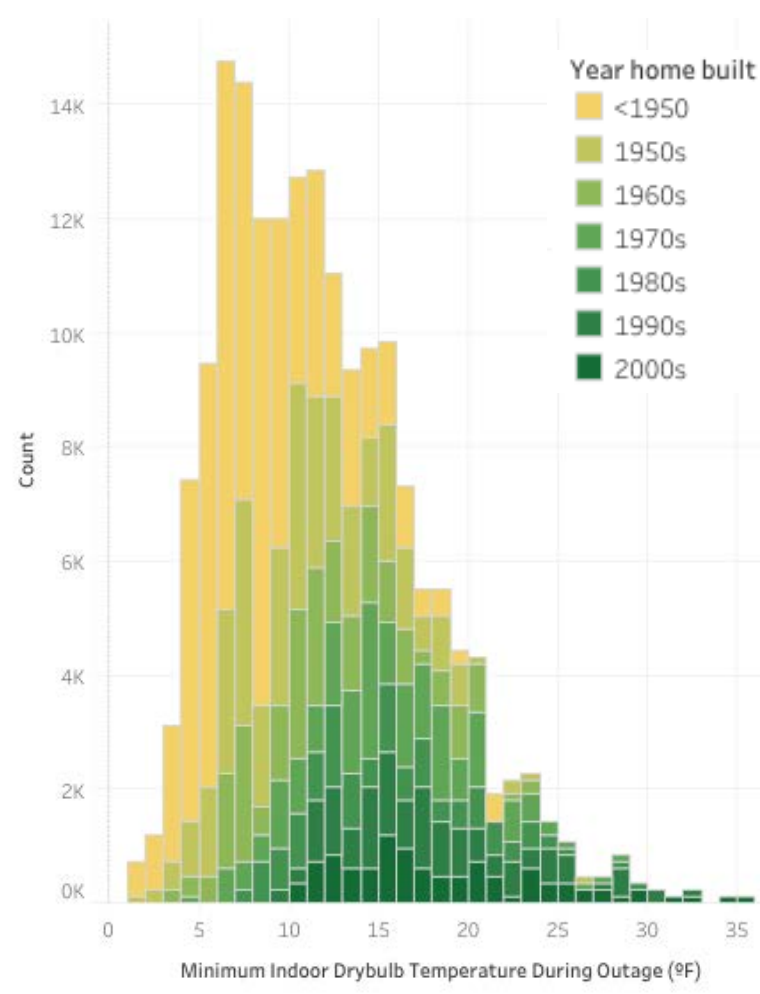

Figure 1. Internal temperature trajectories (left) and distribution of minimum indoor temperatures (right) for buildings in Buffalo, New York, during a power interruption resulting from a hypothetical 12-hour ice storm, as modeled in ResStock

Newer homes, presented in green, typically maintained a livable internal temperature for longer during the hypothetical ice storm, and they maintained higher temperatures overall over the course of the outage.

In the case of the simulated power interruption during a heat wave (Figure 2, page 17), some of the newer, more efficient homes stayed within the livable range, even during the longer four-day outage. ${ }^{11}$ During the heat wave, the outdoor WBGT actually dropped below most of the indoor WBGT values, as the power interruption was modeled (1) as having occurred at the peak of the heat wave, when the grid was likely to be most stressed, and (2) without consideration of potential changes in occupant behavior, which can be difficult to predict. For example, occupants could open windows to facilitate equilibrating with the lower outdoor WBGT (Figure 2); however, such actions (or inaction) could ultimately depend more on external factors (e.g., fear of crime) than on personal comfort. Given this uncertainty and insufficient supporting data, potential mitigating actions (unrelated to the use of electric equipment) were not considered in our preliminary resilience analysis effort.

\footnotetext{
${ }^{11}$ Results from this preliminary resilience analysis distinguish between two distinct groups of homes: those with air conditioners and those without (Figure 2). As the outage progressed, the two groups gradually merged.
} 


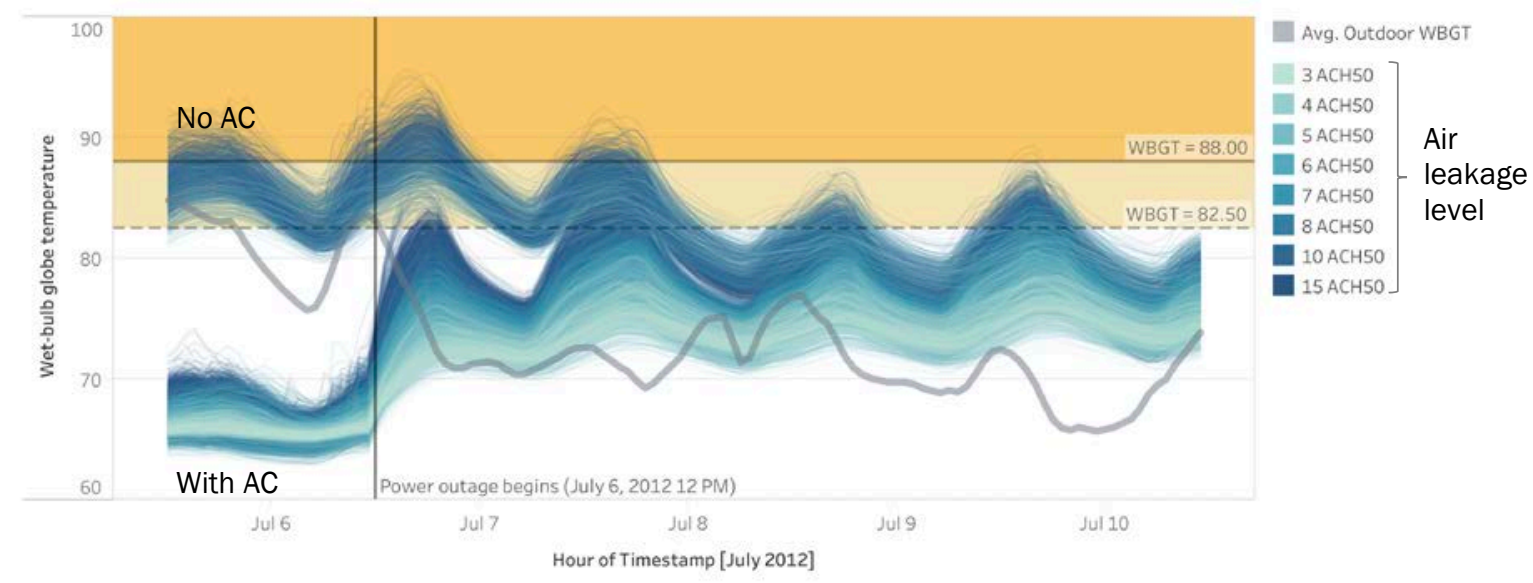

Figure 2. Internal temperature trajectories for buildings in Chicago, Illinois, during a power interruption resulting from a heat wave, as modeled in ResStock

During the heat wave, two distinct groups of homes were apparent: those with air conditioning and those without. When the power interruption occurred at noon on July 6 , the two clusters began to merge. Of the homes with air conditioning, those that were more airtight tended to maintain more comfortable indoor air temperatures.

\section{Summary and Future Work}

Based on research completed under this study, ResStock can now simulate a power outage, and it can evaluate the thermal resilience of the residential building stock during a power outage that is coincident with adverse weather conditions. The results described are intended as a demonstration of the newly added capabilities, which could be used to simulate power interruptions at different times and in additional locations. However, these initial results showed that more-efficient buildings tended to be more resilient as well. An important next step in this type of analysis is translating the performance of buildings into economic value, which could take various forms (e.g., the value associated with improved personal comfort and avoided private insurance or public emergency response expenditures for relocating affected residents).

The literature validates the use of the EnergyPlus simulation engine for indoor occupant heat stress analysis (Holmes 2016), but additional work is needed to validate ResStock assumptions about the distribution of thermal capacitance across the housing stock. The thermal capacitance of construction materials is well understood, but the range in the quantity of furniture, books, and other contents of homes contributing to thermal capacitance is more uncertain. Another opportunity for improvement is in modeling how different occupants respond to outages during extreme events, which may include opening windows or closing window blinds during a heat wave, and boiling water or running the water heater during a cold wave (if natural gas were available for cooking or water heating). Accounting for these potential changes to occupant behavior during an outage would require efforts in model development as well as the collection and implementation of supporting data.

\subsection{Probabilistic Resource Adequacy Suite (PRAS)}

The Probabilistic Resource Adequacy Suite (PRAS) ${ }^{12}$ simulates different combinations of transmission and generation outage events on the bulk power system to quantify the risk of unserved load events resulting from shortfalls in the supply or deliverability of capacity. These risks can be expressed in terms of the loss-of-load expectation (LOLE), which is the

${ }^{12}$ https://nrel.github.io/PRAS/ 
count of the average number of time-steps (e.g., hours) during which a shortfall event is expected to occur during the study period, and expected unserved energy (EUE), which is the average total magnitude of shortfall expected over the study period.

This analysis studied the resiliency impacts of adding energy storage devices to a regional grid in order to ride through a multiday fuel supply disruption for natural gas-fired generation units. The analysis used EUE as the primary resilience metric in order to quantify reductions in the depth of shortfall under different storage installations (e.g., no storage, a single 100megawatt four-hour storage unit, and six 100-megawatt, four-hour storage units). In the scenario considered, a natural gas supply disruption in a region of the Reliability Test System - Grid Modernization Lab Consortium (RTS-GMLC) (Barrows et al. 2019) ${ }^{13}$ forced all gas combustion turbine and combined cycle units in that region offline for 58 hours before allowing them to randomly return to service (based on their probabilistic mean-time-to-repair parameters). Other generators in the system experienced normal outage conditions (probabilistic outages and repairs were based on unit-level mean-time-to-fail and mean-timeto-repair properties).

Under normal operating conditions (no fuel supply disruption; dark purple line), no unserved energy was experienced across any of the simulations (Figure 3). However, more than 100,000 separate simulations of the previously described disruption scenario, the system experienced 111 megawatt-hours (MWh) of unserved energy with no storage installed (red line in Figure 3), $57 \mathrm{MWh}$ with the single device installed (blue line), and $3 \mathrm{MWh}$ with six devices installed (green line), on average. The apparent under-performance of the simulated battery systems - e.g., the $100 \mathrm{MW} / 400 \mathrm{MWh}$ battery reduces EUE by $54 \mathrm{MWh}$ - was the result of averaging across all simulations, as the EUE was zero in many of the simulations, even under the disruption scenario.

As PRAS uses "greedy" rule-based dispatch heuristics to inform storage charge and discharge profiles (not intertemporal optimization), it cannot distinguish between scenarios with long, short, or no preparation time before an event. However, the nature of these dispatch rules (charge storage whenever possible, and only discharge as a last resort to avoid dropped load) and the accompanying assumption that other possible (unmodeled) operating modes do not reduce the resource's ability to provide energy when called on to avoid a shortfall could be interpreted as consistent with a scenario in which an operator either has some degree of advance knowledge of a resiliency event or at least holds energy reserves in anticipation of a possible need (such as with Tesla's Powerwall Storm Watch mode).

In keeping with current standard practice in probabilistic resource adequacy assessment, PRAS considers random generator and line outages (which may contribute to dropped load) as occurring completely independently of other potential failures on the system. This is clearly a poor assumption in the context of resilience events such as extreme weather or infrastructure attacks. A more realistic representation would allow outage or repair probabilities to vary across time as a function of environmental conditions (e.g., temperature and wind speed), contemporaneous outage events, or other common factors that may affect multiple grid assets and lead to correlated outages or repair delays. Future work could build on recent efforts in deriving conditional asset failure probabilities given specific environmental conditions (Murphy et al. 2019) to better characterize the conditional (given some extreme weather resilience event) resource adequacy of a power system, moving beyond standard reliability studies which focus only on typical operating conditions.

13 “Reliability Test System - Grid Modernization Lab Consortium,” https://github.com/gridmod/rts-gmlc. 
Transmission constraints between the three regions of the test system were also not enforced in this analysis, and they would likely increase expected unserved energy if considered in future analyses.

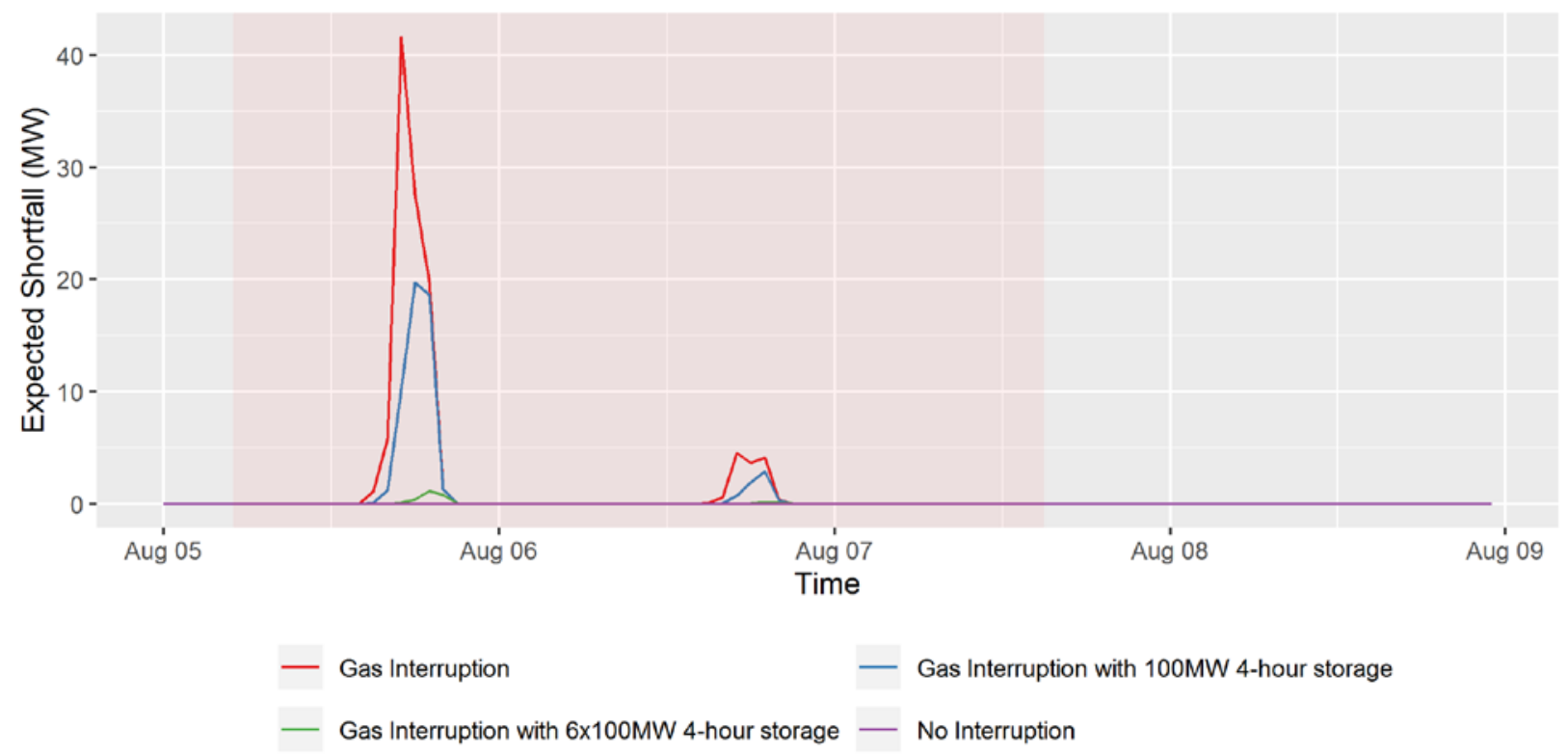

Figure 3. Expected unserved energy across natural gas disruption scenarios with varying levels of energy storage capacity, as modeled in PRAS

The four lines demonstrate the expected shortfall (in megawatts) that could occur under scenarios with varying assumptions about natural gas supply interruption and installations of four-hour battery storage systems. Obtaining the total lost load (in megawatt-hours) requires multiplying the expected magnitude and duration of the shortfall.

Finally, though this preliminary resilience analysis employed an energy-based system performance metric, an estimate of the economic consequences associated with EUE could be derived by multiplying the magnitude of the expected energy shortfall by some predetermined value of lost load (VoLL), expressed in terms of currency per unit energy (e.g., \$/MWh). The expected (average) value provided by an investment designed to improve system resilience could then be expressed as the product of the system's VoLL and the decrease in EUE achieved by the upgrade. The true opportunity cost of an energy shortfall varies widely by consumer and end use, with system-level average estimates in the United States typically ranging from $\$ 2,000 / \mathrm{MWh}$ to $\$ 20,000 / \mathrm{MWh}$. However, a static VoLL is likely not appropriate for use in resilience analyses, because the time-dependence of the VoLL becomes increasingly important in extended-duration power interruptions. This topic is discussed in detail in the following sections. 


\section{Adapting Least-Cost Optimization Models for Resilience Analysis}

In contrast to the efforts presented in Section 3, the implementation of resilience metrics in SIIP::Power, ReEDS, and REopt involved modifying the constraints or objective functions that define the solutions in these least-cost optimization models. Moreover, these models are currently formulated to consider only deterministic threats (reflected by exogenous scenario definitions) and outcomes (based on constraints within the models' objective functions). Therefore, the results presented in this section describe how accounting for a given resiliencetesting event - and its consequences - influenced the least-cost energy investment and operational decisions made in the models, without considering uncertainties about event forecasts or recovery times.

In the case of the SIIP::Power analysis, which simulates unit commitment and dispatch, we expect to observe changes in the operations of the bulk power system, which would influence both (1) the timing and duration of power interruptions experienced by customers that are served by a given node and (2) the overall system costs associated with a long-duration outage. The former outcome could be thought of as a scheme to serve critical loads during an event, given the higher customer (and potentially broader societal) damages associated with an extended period of lost load for a critical service type (e.g., hospitals, fire stations, or police stations). In the case of the long-term planning models (ReEDS and REopt), the expected outcome is a change in the optimal energy investment, which follows from changes in the cost-benefit analysis for various investment options when accounting for the value of improved resilience (either directly or indirectly).

\subsection{Scalable Integrated Infrastructure Planning: Power Systems Toolkit (SIIP::Power)}

The Scalable Integrated Infrastructure Planning: Power Systems Toolkit (SIIP::Power) provides a flexible framework for defining and solving a variety of power systems analysis problems. The toolkit enables a variety of standard unit commitment and economic dispatch formulations, including (1) linear and non-linear power flow and (2) utilities to enable simulations of sequential and nested interdependent problems. SIIP::Power is currently focused at transmission level power system data. The framework leverages parametric dispatch to enable flexible mathematical formulations and simulation assemblies, and it supports optimization and simulation model solutions with modularity between data, problem compilation, and solution techniques. The overarching SIIP framework has been applied to power systems and municipal water systems, and there are plans to enable simulations of other infrastructure systems (e.g., natural gas and transportation).

For this preliminary resilience analysis, we used the features of SIIP::Power that represent an adapted production cost modeling framework. This demonstration involved hourly resolution and detailed load, transmission, and generator fleet data for the RTS-GMLC (Barrows et al. 2019), which consists of three regions with 74 buses and 155 generators. In particular, we exercised the production cost modeling framework in SIIP::Power to determine the least-cost generation commitment and dispatch schedule to meet system demand. Beyond the standard physical and regulatory requirements of system operations, the least-cost solution in SIIP::Power was also informed by our chosen resilience metric, which is based on a duration-dependent value of lost load (VoLL). The formulation for duration-dependent VoLL is represented by a series of sets, which are presented in the appendix. 
Most production cost models can represent generator and line outages, but they treat the VoLL as a constant value that does not vary over the duration of a power interruption; therefore, lost load is the decision variable. In this case study, we model a VoLL that varies as a function of the time since service was interrupted. This duration-dependent VoLL is determined from a flexible framework that defines how the VoLL evolves over the course of a long-duration power interruption for an individual customer type, accounting for the type and timing of the underlying cause of the outage (Ericson and Lisell 2018).

In this preliminary resilience analysis, the duration-dependent VoLL varied (1) over the duration of the power interruption and (2) by node, based on the load served by that node. This information was used by the model to select which buses to serve at each time-step when there was insufficient energy to serve all loads. The mathematical formulation is similar to a classic unit commitment and economic dispatch formulation, but in addition to deciding the commitment of power plants, our decision variable is whether to serve power to a bus. The objective function is to minimize the total system cost-including the fixed outage cost, duration-dependent outage cost, and generation costs.

In terms of the power interruption scenario represented, we explored an event with no forecast availability, in which 1,600 MW (or 15\%) of generation capacity were lost for 12 hours; this degradation was such that the system could serve all of the scheduled load. The modeling approach to simulate system dispatch during the event was very similar to solving sequential decision problems, such as in an economic dispatch problem; in particular, the commitment decision was assumed to be fixed, ${ }^{14}$ as units may have already been online, and those that were not could take too long to come online. The model solved one time period (hour) with an initial condition and four hours of look-ahead (in this analysis), which informed how the duration-dependent outage cost would rise at each bus if its load was not served. Given this, the model selected which buses to serve, allowing users to explore the extent to which system schedules could be adjusted to reduce the consequences of a longduration event, based on a detailed understanding of the costs incurred by customers at a given bus.

To isolate the effects of considering our VoLL-based metric, we exercised the production cost modeling framework in SIIP::Power with either (1) a constant VoLL across all buses or (2) a duration-dependent VoLL, which also varies by bus. Across both implementations of VoLL, we found a similar level of total lost load (in MWh); however, operational differences were observed as the model was exposed to different customer costs. In particular, providing the grid operator with information about how customer costs vary as a function of outage duration and location (bus) resulted in reductions in both overall system costs (by $22 \%$ ) and the maximum number of hours of outage experienced by any bus on the network (from 15 hours to 6 hours). However, the number of buses that experienced an outage increased when considering the duration-dependent VoLL, as the operator was encouraged to restore power and move the outage to a different bus after a few hours, when the cost of not serving a bus increased. Therefore, the duration-dependent VoLL drove the model to behave like a rolling brownout, affecting (1) more customers but (2) each customer for fewer hours.

Figure 4 shows an example of the difference in operations when considering a durationdependent (top row) versus static (bottom row) VoLL in Region 1 of the RTS-GMLC. As generation assets in all three regions were affected by the simulated outage, the duration-

\footnotetext{
14 The assumption that unit commitment is fixed during an event may be valid during events where (1) the forecast window is short and (2) the event duration is not very long.
} 
dependent VoLL model chose to start the outage in Region 1 for the first few hours, and then moved the outage to Region 2 (not shown). When the net load in the system started to rise in the evening, the outages were moved to Region 1 for a few periods and then split among all the regions on the buses that were unaffected earlier. However, it is important to note that such a response could be more challenging (or even impossible) if the event involved moreextensive failures along the transmission network.
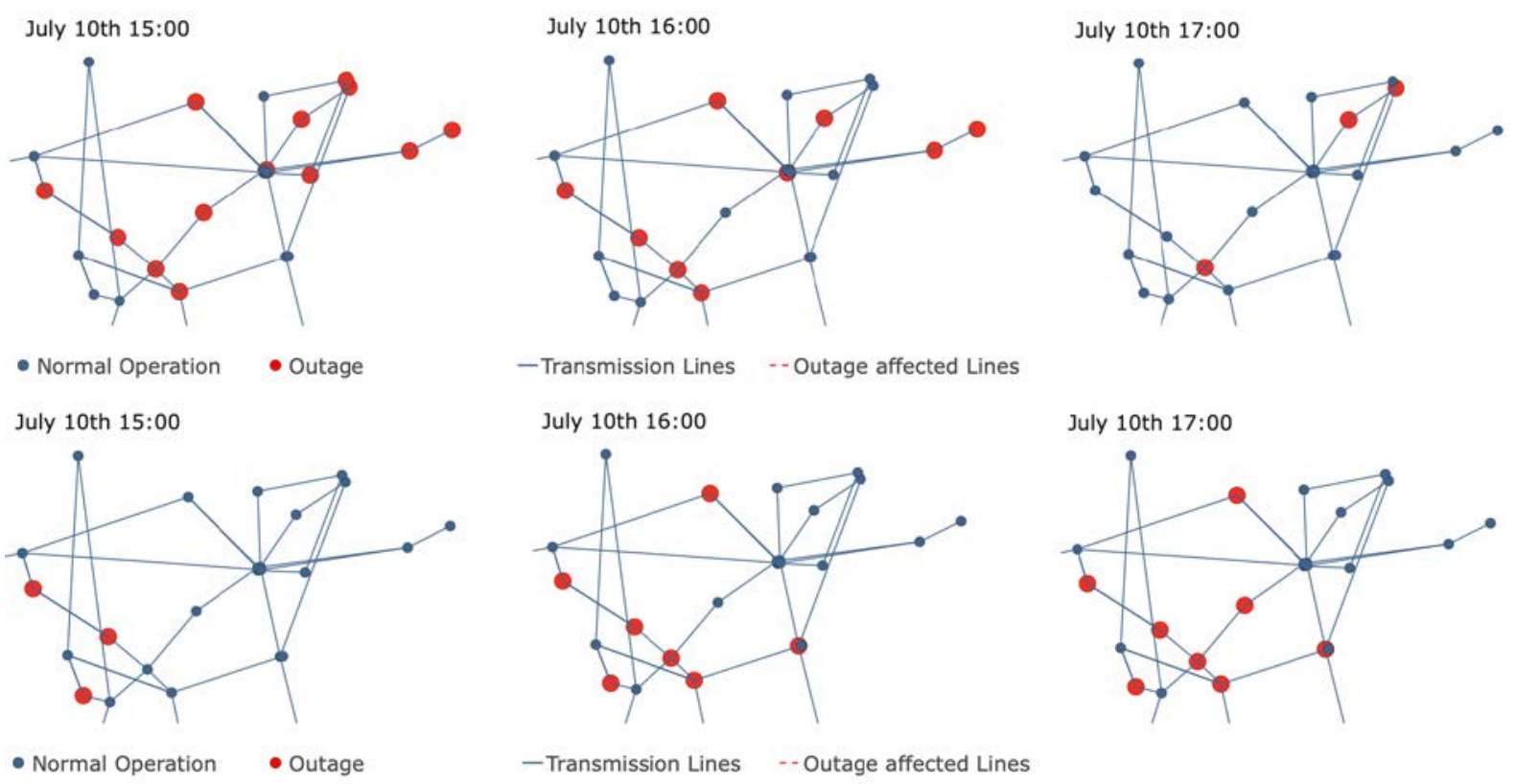

Figure 4. Under degraded conditions, considering a duration-dependent value of lost load resulted in a modified system dispatch, which reduced outage duration at each bus and overall system costs, as modeled in the production cost model framework in SIIP::Power.

Results shown here represent system dispatch in Region 1 of the RTS-GMLC under a power interruption scenario that resulted in a $15 \%$ loss in available generation capacity for 12 hours. The top row shows the dispatch pattern that resulted from consideration of a duration-dependent VoLL, whereas the bottom row considers only a static VoLL.

A different dispatch was observed when using a static VoLL, in which case outages were primarily clustered around the buses with low demand. The outages sometimes moved as bus demand changed, such that the model minimized system cost by serving as much load as it could with the available generation assets while being forced to make a binary decision on whether to serve a bus. This led to some end users suffering longer outages than they did in the duration-dependent VoLL scenario (15 hours versus 6 hours). Finally, the number of locations affected was lower in the static VoLL scenario, but the cost of the outage increased.

While results will vary by event and customer type, this case study showed that knowledge of the duration-dependent (as opposed to a static) VoLL at each node could resulted in different dispatch decisions and a lower total outage cost. Future research could confirm this finding, especially through additional model development and case studies. For example, in this preliminary resilience analysis, we assumed the generator unit commitment schedule (i.e., the on/off status of generators) was predetermined and not subject to re-optimization during the event. This assumption was made for modeling simplicity and computational tractability, but in future work, the approach could be extended to reoptimize unit commitment decisions to further optimize operations during resilience events. Such a capability would be especially valuable in evaluating the impacts of forecast availability, in terms of how unit commitment and dispatch ahead of an event could influence available energy and system costs. 
A second future research direction could involve exploring how dispatch patterns and system costs might be altered when it is possible to avoid outages to the customer types with the highest VoLLs (e.g., critical services such as hospitals, fire stations, and police stations, or customers with high economic impact within the region). The production cost modeling framework in SIIP::Power allows multiple VoLL curves to be defined at an individual node, so that different customer types can be represented. Future work could leverage this capability and allow for partial-load on a node to be served, in order to evaluate whether there are diminishing returns (in the form of system-cost savings) with increasing levels of resolution for customer cost information.

\subsection{Regional Energy Deployment System (ReEDS)}

The Regional Energy Deployment System (ReEDS) is a bottom-up electric sector capacity expansion model for the contiguous United States that finds the least-cost construction and operation of generation, storage, and transmission assets between 2010 and 2050 (Cohen et al. 2019). The 2018 version of ReEDS (v2018) was used in this study (Cole et al. 2018), and that version of the model simulates the bulk power system sequentially in two-year timesteps, by minimizing the 20 -year present value of investment and operation under currentyear conditions. ReEDS is resolved into 134 supply-demand balancing areas and includes a reduced-form dispatch in 17 intra-annual time-slices: four per season with a peak time-slice to better capture reserve requirements. Balancing areas are connected by an aggregated $\sim 300$ line transmission system that can expand to meet system needs. The model includes a suite of commercial or near-commercial generation and storage technologies, with particular detail in renewable energy resource quality, cost, and variability. Capacity and generation of most technologies are aggregated to the balancing area level, with no explicit representation of individual units or plants. ${ }^{15}$

The level of aggregation in v2018 ReEDS prohibits the model from representing unit- or linespecific outages and localized short-term interruptions on the bulk power system. ${ }^{16} \mathrm{By}$ construction, the model also has no clear way to represent "no preparation" scenarios; it can only be manipulated to "plan for resilience" by changing aggregate long-term system expectations in ways that incentivize responses that could improve resilience through the adjustment of generation or transmission expansion and operation. As a result - and in contrast to the SIIP::Power and REopt analyses - this preliminary implementation of resilience metrics in v2018 ReEDS represents modifications to the constraints within the model, as opposed to modifications to its objective function.

Five model constructs were used to analyze ways to plan for resilience in v2018 ReEDS (Table 5); these constructs reveal differences in the capacity mix, generation mix, and transmission expansion under a variety of approaches for resilience planning. Results from this ReEDS analysis thus provide insights into how systems might plan for greater resilience. The cost impacts of these responses were assessed using changes in national average electricity price and changes in 2017-2050 present value of total system costs, both relative to a reference case.

\footnotetext{
${ }^{15}$ Exceptions to this statement include the limited instances where a modeled balancing area includes only one plant of a given generator type.

${ }^{16}$ Note that recent developments in the ReEDS model have enabled a flexible representation of generation units, which can be represented as either individual units or as aggregated representative plants (Cohen et al. 2019; Cole et al. 2019). Replicating this analysis in more recent version of ReEDS could allow for representation of short-term outages of individual generating units or blocks of capacity.
} 
Table 5. Model Constructs Used to Analyze Resilience Planning in v2018 ReEDS

\begin{tabular}{lll}
\hline $\begin{array}{l}\text { Modification } \\
\text { (Scenario Abbreviation) }\end{array}$ & Intent & $\begin{array}{l}\text { Model Constraints and } \\
\text { Parameter Range }\end{array}$ \\
\hline $\begin{array}{l}\text { Increased operating reserve } \\
\text { requirement }\end{array}$ & $\begin{array}{l}\text { Greater flexibility responding } \\
\text { to short-term outages }\end{array}$ & $\begin{array}{l}3 \%-15 \% \text { of load required as } \\
\text { spinning reserves }\end{array}$ \\
\hline $\begin{array}{l}\text { Increased planning reserve } \\
\text { requirement }\end{array}$ & $\begin{array}{l}\text { Improve resource adequacy } \\
\text { under outages at peak }\end{array}$ & $\begin{array}{l}\text { Regional planning reserve } \\
\text { requirement increased by 40\%a }\end{array}$ \\
\hline $\begin{array}{l}\text { Higher generator outage rates } \\
\text { Plan for more frequent } \\
\text { generator outages } \\
\text { outage rate }\end{array}$ & $\begin{array}{l}\text { Plan for more frequent } \\
\text { transmission outages }\end{array}$ & $\begin{array}{l}\text { Generator forced outage rate } \\
\text { increased by 50\%a }\end{array}$ \\
\hline $\begin{array}{l}\text { Higher transmission outage } \\
\text { rate plus option to purchase } \\
\text { "resilience capacity" }\end{array}$ & $\begin{array}{l}\text { Allow construction of resilient } \\
\text { transmission capacity, e.g., } \\
\text { undergrounding }\end{array}$ & $\begin{array}{l}\text { Transmission forced outage } \\
\text { rate increased up to 50\%a }\end{array}$ \\
\hline
\end{tabular}

a Parameter increases or reductions reflect percent changes relative to default assumptions in the 2018 version of the ReEDS model.

Capacity expansion results across all scenarios showed that the strategy for resilience planning depends on the problem being addressed. A higher expectation of short-term outages required keeping more capacity on standby to provide operating reserves, while building some additional capacity to meet the planning reserve requirement (i.e., to ensure resource adequacy). Under the reference technology and other assumptions in ReEDS v2018, combined-cycle natural gas capacity is utilized to provide these additional operating reserves. Moreover, concerns about resource adequacy at peak loads warrants construction of more simple-cycle gas turbines and additional solar photovoltaics (PV) or combined-cycle natural gas technology, depending on the capacity credit of local PV capacity. Expecting more frequent generator outages had little impact when implemented as an average change, but this result could differ from analysis of specific large-scale outage events. Expecting more transmission outages warrants some additional redundancy in the transmission system, but expensive "hardening" measures were not competitive when based purely on least-cost electricity system operation.

For the range of scenarios examined, impacts on average electricity price were relatively small. The increase was $\$ 1.3 / \mathrm{MWh}$ or less for all except the increased operating reserve requirement scenarios, which increased prices by as much as $\$ 6.3 / \mathrm{MWh}$ but typically by $\$ 3 / \mathrm{MWh}$ or less. Incremental 2017-2050 system costs were up to $\$ 32$ billion, which is about a $1 \%$ increase from the nominal value of $\$ 3,173$ billion. However, this analysis did not consider outage or lost-load costs outside the construction and operation of the electricity system, so it does not fully assess the cost of outages and the value of reducing them. In addition, the ReEDS model does not include an explicit representation of the natural gas system, so the strategies and costs identified in this analysis do not consider interdependency factors between the natural gas and bulk electric systems. Finally, all changes were applied across all regions and time periods in this analysis, but future work could be more targeted. 


\subsection{Renewable Energy Optimization (REopt)}

REopt is a techno-economic decision support model used to optimize energy systems for buildings, campuses, communities, and microgrids (Cutler et al. 2017). The primary application of the model is to optimize the integration and operation of behind-the-meter energy assets, including renewable energy, generators, energy storage, and dispatchable loads. Formulated as a mixed-integer linear program, REopt solves a deterministic optimization problem to identify the optimal selection, sizing, and dispatch strategy of technologies chosen from a candidate pool, such that electrical and thermal loads are met at every time-step at the minimum life cycle cost. The model considers capital costs, operating expenses, operating revenues, incentives, and tax benefits in the life cycle cost calculation.

REopt has previously been adapted for resilience analyses which were designed to identify optimal backup power systems, taking into account the uncertainty in outage start time and duration and/or the value of lost load (Anderson et al 2017, 2020; Laws et al. 2018, forthcoming). In the present research effort, we demonstrated the latter consideration by incorporating an avoided cost of power interruption ${ }^{17}$ into the lifecycle cost calculation for a PV and battery energy storage system design. Then, a solar and energy storage system was designed to maximize economic benefit during an assumed system lifetime of 20 years.

The lifetime economic benefit is measured in terms of the net present value (NPV) of the system, or the net difference between the benefits and the costs of the project, in current values in U.S. dollars. The project benefits include the energy bill savings delivered by the PV and battery storage systems during normal grid connected operation, as well as the additional benefit of surviving all or part of a grid outage. The project costs include the capital costs of installing PV and storage, system operating and maintenance expenses, and the cost of any outage period not survived. A project with a negative NPV indicates the cost to install and maintain the system would be greater than the savings realized over time. A system with a positive NPV indicates it would be less expensive to build and operate the system than to continue normal operations without it.

Within this overarching framework, two scenarios were evaluated: one that placed no value on resilience, and one that incorporated a static value of resilience (in terms of dollars lost per hour of power interruption). ${ }^{18}$ As previously noted, the use of a static VoLL would likely be inappropriate for long-duration outages, in which estimates associated with the mature form of the metric break down. Under such conditions, costs become increasingly complex and uncertain (e.g., due to cascading effects into other critical sectors), and it is generally believed that economic damages vary non-linearly with the duration of power interruption.

For scenarios in which resilience was not valued, the cost associated with the power interruption was assumed to be zero; in other words, these scenarios ignored any costs associated with asset damage or business interruption. When resilience is assigned a value, the cost of the simulated power interruption can be reduced by the ability of a resilient backup power system to survive some, or all, of anticipated grid outages. The results of the REopt analysis are shown in the two graphs of Figure 5, where resilience is not valued (left) and where it is valued (right) (Laws et al. 2018).

\footnotetext{
${ }^{17}$ The simulated grid outage events were based on the customer average interruption duration index metric, which is equal to 2.09 hours per year at the analyzed location.

18 The assumed value of resilience in this analysis was $\$ 2,386$ per hour, which can be divided by the load at this site to arrive at a dollar-per-megawatt hour value of resilience.
} 


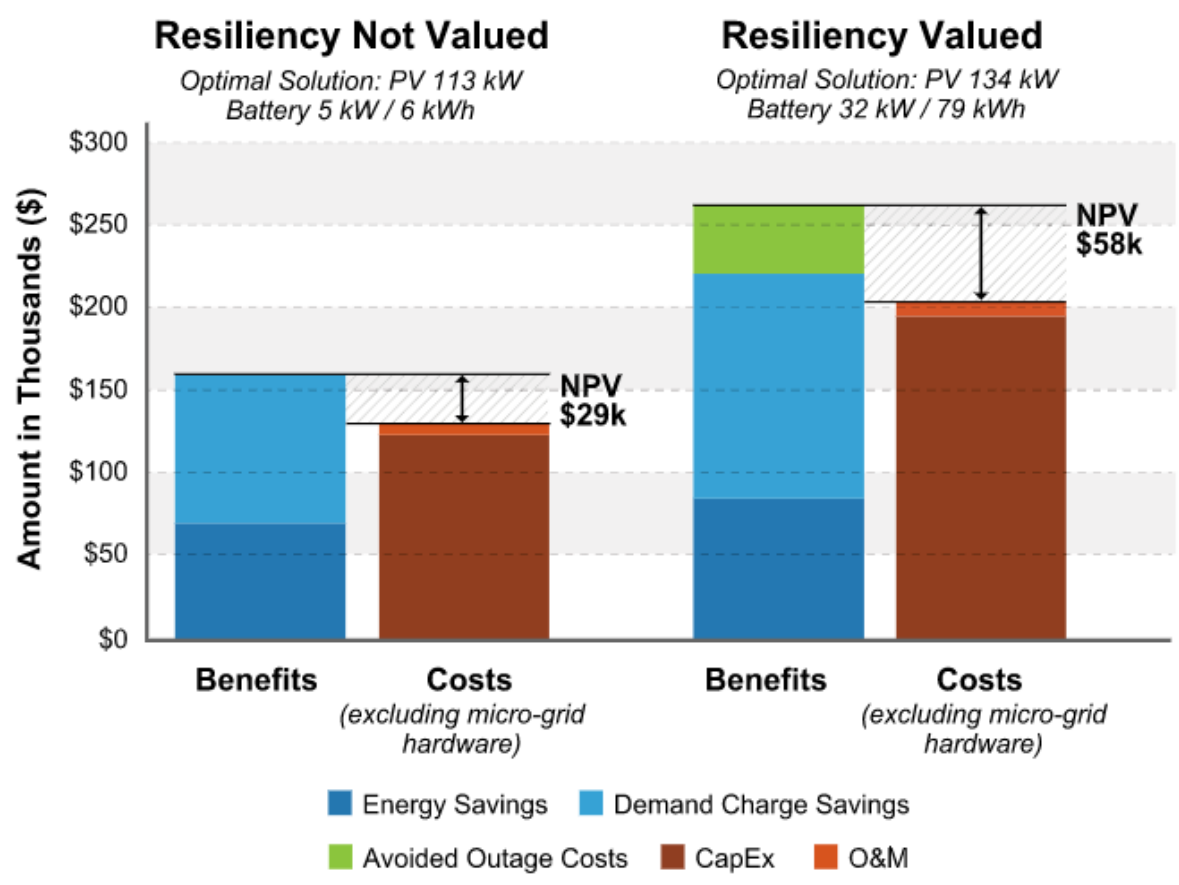

Figure 5. Accounting for the value obtained by mitigating the power interruption experienced by a facility or campus resulted in a cost-optimal backup power system that is larger and incorporates longer-duration storage, as modeled in REopt.

CapEx = capital expenditures, $\mathrm{O} \& \mathrm{M}=$ operation and maintenance

The results shown in Figure 5 indicate that valuing resilience may change the cost-optimal design of a backup power system. For example, the size of the PV system increased from $113 \mathrm{~kW}$ to $134 \mathrm{~kW}$ when accounting for a value of resilience, and battery system size increased from $5 \mathrm{~kW} / 6 \mathrm{kWh}$ to $32 \mathrm{~kW} / 79 \mathrm{kWh}$. Furthermore, the NPV of the investment increased from $\$ 29,000$ to $\$ 58,000$, which primarily reflects that the larger system can sustain the critical load for longer and can therefore avoid more of the outage cost.

The example presented here includes a static value of resilience that did not vary over time. Future work could examine how a duration-dependent value of resilience impacts system design decisions and economics, which could be particularly important for longer-duration resilience events. We also plan to explore the impact of modeling outage distributions where the frequency and length of outages varies over the course of the year. This could become increasingly important as the probability of extreme events increases. Finally, this analysis assumed all load in a given hour of outage must be sustained to avoid the outage cost. Future work we do will examine the value that could be provided by systems that meet only a fraction of the load at a given time. This may be important for understanding how systems should be sized and dispatched for maximum economic benefit. 


\section{Discussion}

The research presented in this report was motivated by a growing need among energy industry stakeholders to evaluate the resilience of their systems to a variety of threats. In general, previous frameworks have outlined the steps necessary to evaluate resilience, which can be summarized through linkages among various research components (Figure 6).

\section{Scenario $\Rightarrow$ Simulation $\Leftrightarrow$ Resilience Metric $\Leftrightarrow$ Optimization $\Rightarrow$ Decisions}

Figure 6. Components of a comprehensive resilience analysis

A perfect resilience analysis would involve detailed approaches for each individual component in Figure 6. However, this level of detail is prohibitively "expensive," in terms of the corresponding data and computational requirements associated with each individual component and the linkages across them. In an effort to avoid "great being the enemy of good," researchers typically make simplifying assumptions for certain components in the process diagram and approach others with a higher level of fidelity and granularity. Such tradeoffs are needed to ensure resilience analyses remain tractable, even for organizations with the most robust computational resources.

Within the research community and energy industry, discussions often center on the need for detailed approaches to resilience metrics. However, such requests may only address part of the ultimate need, as the effectiveness of a metric depends strongly on the ability to evaluate it in a sophisticated and rigorous manner. For example, EUE is a mature reliability metric that has been well-vetted and implemented in both postmortem and prescriptive analyses. However, the value associated with the EUE metric is primarily rooted in the ability to translate how various grid operations and investment decisions would impact EUE, through the utilization of sophisticated data analysis and simulations tools. Similarly, even a seemingly perfect resilience metric would be of little use without simulation and optimization models that can accurately evaluate how populating that metric would lead to different investment and/or operational decisions.

The present study was rooted in a similar premise, which is that newly developed resilience metrics may not be the most appropriate answer to the growing needs regarding energy sector resilience analysis. Instead, we chose to approach resilience analysis by implementing simplified power interruption scenarios and resilience metrics in highly sophisticated simulation and optimization tools. To do so, we modified model inputs, constraints, and/or objective functions to capture the benefits associated with improved resilience, from a variety of stakeholder perspectives. Across the full suite of models, we quantified resilience in energy models designed to represent generation, transmission, capacity expansion, distributed energy resources, and energy end use. Each model yielded different results and insights, which are summarized in Table 6 . 
Table 6. Summary of Preliminary Resilience Analyses in Existing NREL Tools

\begin{tabular}{|c|c|c|c|}
\hline Model Name & $\begin{array}{l}\text { Power Interruption } \\
\text { Scenario Name }\end{array}$ & Resilience Metric & Analysis Findings \\
\hline ResStock & $\begin{array}{l}\text { Both Short and } \\
\text { Long-Duration } \\
\text { Power Interruptions } \\
\text { with No Preparation } \\
\text { Time }\end{array}$ & $\begin{array}{l}\text { Social consequence } \\
\text { measured via (a) time to } \\
\text { unsafe indoor conditions } \\
\text { during adverse outdoor } \\
\text { conditions or (b) } \\
\text { minimum/maximum } \\
\text { indoor temperature }\end{array}$ & $\begin{array}{l}\text { More efficient buildings tend to } \\
\text { be more resilient because they } \\
\text { can maintain livable indoor } \\
\text { temperatures longer during } \\
\text { interruptions in the supply of } \\
\text { electricity or natural gas }\end{array}$ \\
\hline PRAS & $\begin{array}{l}\text { Long-Duration } \\
\text { Power Interruption } \\
\text { with No Preparation } \\
\text { Time }\end{array}$ & $\begin{array}{l}\text { System performance } \\
\text { measured via expected } \\
\text { unserved energy }\end{array}$ & $\begin{array}{l}\text { Adding energy storage devices } \\
\text { could reduce the depth of } \\
\text { shortfall associated with a long- } \\
\text { duration fuel supply disruption }\end{array}$ \\
\hline SIIP::Power & $\begin{array}{l}\text { Long-Duration } \\
\text { Power Interruption } \\
\text { with No Preparation } \\
\text { Time }\end{array}$ & $\begin{array}{l}\text { Economic consequence } \\
\text { measured via location- } \\
\text { and duration-dependent } \\
\text { value of lost load }\end{array}$ & $\begin{array}{l}\text { Overall system costs and the } \\
\text { maximum hours of outage } \\
\text { experienced by a bus on a } \\
\text { network could be reduced } \\
\text { through operational changes } \\
\text { that are driven by a more } \\
\text { detailed understanding of the } \\
\text { duration-dependence of the } \\
\text { value of lost load }\end{array}$ \\
\hline ReEDS & $\mathrm{N} / \mathrm{A}$ & $\begin{array}{l}\text { Attribute-based metric of } \\
\text { redundancy }\end{array}$ & $\begin{array}{l}\text { Resiliency concerns can } \\
\text { influence the optimal } \\
\text { investment portfolio in different } \\
\text { ways, depending on whether } \\
\text { you are concerned about } \\
\text { operating reserves, resource } \\
\text { adequacy at peak loads, more } \\
\text { frequent generator outages, or } \\
\text { more transmission outages }\end{array}$ \\
\hline REopt & $\begin{array}{l}\text { Short-Duration } \\
\text { Power Interruption } \\
\text { with No Preparation } \\
\text { Time }\end{array}$ & $\begin{array}{l}\text { Avoided economic } \\
\text { consequence measured } \\
\text { via a static "value of } \\
\text { resilience," or the value } \\
\text { associated with mitigating } \\
\text { power interruptions for } \\
\text { the end user }\end{array}$ & $\begin{array}{l}\text { Accounting for the benefits } \\
\text { associated with surviving all or } \\
\text { part of a grid outage drives } \\
\text { increased in the PV capacity, } \\
\text { energy storage duration, and } \\
\text { net present value of the cost- } \\
\text { optimal backup power system }\end{array}$ \\
\hline
\end{tabular}

Beyond the pragmatic approach of the present report, an alternative approach would be to engage in more-extensive model development and/or linkages to improve the ability to represent multiple components of resilience analysis with higher fidelity. For example, with abundant financial and computational resources, one could develop a new package that both modeled each component in detail and linked those detailed models through automated processes. In particular, for a given power interruption scenario (e.g., a hurricane), the overarching package would simulate the impacts of different scenarios of its realization (e.g., different tracks, strengths, and preparatory responses of system operators), similar to the approach we have taken in ResStock and PRAS. Those simulations would then be used to help populate metrics that quantify different performance impacts or consequences (e.g., EUE, number of customers with insufficient thermal resilience). In turn, the metrics could be implemented as constraints in different system optimization tools (e.g., ReEDS, SIIP::Power, REopt) to inform which actions would be most cost-effective for improving either system 
(ReEDS, SIIP:: Power) or customer (REopt) resilience. Given appropriate model linkages and automation, the optimization tools could then iterate between the metrics and, sometimes with the simulation tools, to optimize the metric outcome given constraints. Finally, this result is sent to decisionmakers to determine which steps to take to improve resilience.

The methods described represent an optimal approach to resilience analysis, but they come with a set of challenges. First, many of the entities responsible for evaluating and approving resilience investments operate with limited resources and, therefore, it would not be feasible for them to build and operate such a model. Second, there are computational resource challenges associated with such an approach, which would require extensive resources to operate and link multiple high-resolution models. Third, one of the underlying themes of resilience-testing events is that they result in impacts across multiple infrastructure systems; currently, models do not exist for representing these linkages, due to their complex interdependent nature. Fourth, some of the data necessary to define the parameters and variables across the different tools is sparse or unavailable, which introduces challenges associated with verifying the ultimate outcome. Moreover, determining "error bars" within, and across, the underlying tools would be difficult or impossible, given the wide range of sources of uncertainty. None of these challenges is insurmountable, but they rather represent areas of research that would help to improve the ability to perform a more-optimal resilience analysis of energy systems. 


\section{Conclusions and Future Research Needs}

Resilience is receiving much attention in relation to energy systems in general, with particular attention being paid to the supply of electricity. Incorporating resilience considerations into energy decisions would be useful for utilities and local planners, but power system modelers and operators have been challenged by resilience. One of the main challenges has been the limited extent to which resilience metrics have been implemented, tested, and validated in models of the energy system. The scenarios, methods, and metrics by which resilience is quantified vary depending on intent (in the case of analysis more broadly) and the availability of detailed analysis methods and data (in the case of incorporating resilience into an energy sector model). As a result, quantifying, valuing, and monetizing resilience and applying those concepts to energy sector models, plans, and investments has been problematic.

To begin to address this problem, we applied various attributes of resilience in scenario analysis using five different energy sector tools. The chosen set of tools spans a range of modeling approaches, geographic scales, and segments of the energy sector. Moreover, the corresponding set and implementation of appropriate resilience metrics was similarly diverse. Within the detailed simulation models included in this study, resilience analysis took the form of developing new representations of grid outages and providing additional context for the model results. Within the least-cost optimization models, the preliminary resilience analyses involved modifying the constraints and/or objective functions that define the model solutions. Finally, comparison across all of the models and power interruption scenarios yielded the following five findings and areas of needed future research.

\section{A Multilayered System of Metrics}

The tools that were exercised in this research used different metrics, partly because the tools were not developed specifically to model resilience and partly because of the different attributes of resilience that apply to different systems within the power sector. There is no one-size-fits-all metric, nor should one metric be deemed successful for all systems modeling. A multilayered system of metrics will be needed for future resilience work.

Research that helps identify a set of metrics that could be applied in a number of scenarios would be useful to various industries. Though no one metric would solve the decision-making and modeling challenges related to all resilience planning needs, a set of metrics for industry discussion and analysis would be helpful at many scales. Measuring the performance benefits of resilience strategies, along with establishing valuation methodologies for such strategies, would help with enhancing resilience across the energy sector.

\section{Resilience-Value Linkages}

Even if there were a universal method for quantifying resilience, an additional challenge lies in linking resilience to the corresponding value that is retained or added. The current understanding of what customers are willing to pay to avoid long-duration outages is highly limited, and it could benefit from an improved understanding of three key factors:

1. How customers' value of resilience evolves over the temporal arc of a long-term disruptive event

2. The nature, extent, and evolution of system-wide consequences and interactions that are due to sectoral interdependencies (e.g., water, telecommunications, and natural gas) (National Academies of Sciences, Engineering, and Medicine 2017; Kintner-Meyer et al. 2016) 
3. How to translate the impacts of such an event into associated consequences related to degraded health, safety, and economic activity.

Improving the understanding of these three factors would improve the ability to determine an appropriate "value of resilience," but there is significant uncertainty about whether these factors can be rigorously quantified. For example, it is challenging to determine the extent to which a given threat would impact the health, safety, and economic activity of a given region, as this depends on the likelihood, timing, and specific characteristics of the threat that is realized. Moreover, even if the health, safety, and economic impacts of a threat could be quantified, it is very challenging to translate those impacts into financial consequences, which will ultimately indicate to a given stakeholder whether a change in investment or operations is warranted.

\section{Quantification of Resilience Investments}

Accurately quantifying how a given resilience investment could lead to performance improvements (and, in turn, value) requires a more fundamental understanding of the relationship between a threat and its impacts. A particularly important area for future research is the development of methodologies for endogenously representing probabilities for response and recovery activities. For example, recovery timelines may be a function of advanced notice, type, and timing of the threat of interest; available resources; and dependency (or interdependency) with other critical infrastructures. This limitation primarily represents a need for data to inform such a relationship, as the improved understanding could be translated into energy decision models in various ways. For example, a relationship between advanced notice and recovery time could either be represented endogenously-through a model parameter that relates advanced notice with recovery time, accounting for changes in planning costs — or exogenously through scenario definitions.

However, even if such a relationship were well-understood and parameterized, additional model development would be needed to implement it in a wide array of tools. For example, only one of the models explored here can capture one aspect of how sensitive an event's consequences are to the threat: the production cost modeling framework in SIIP::Power can represent advanced notice through different unit commitment schedules, which will influence the amount of available energy and system costs associated with a long-duration outage.

\section{Modeling of Costs and Benefits}

In most cases, trade-offs between the costs and benefits of resilience measures are not currently modeled in power system tools. Modelers tend to measure either the benefit or the cost, but not both. Understanding both sides of the equation is essential to knowing how much resilience is reasonable for investments, which is the focus of Anderson et al. (2020).

\section{New Modeling of Resilience}

An alternative approach to modifying existing tools to enable them to effectively quantify and estimate the value of potential resilience investments would be to develop a new model that is especially designed for energy sector resilience. There would many challenges with such a model, given the broad extent, large number of stakeholders and sectors, data requirements, and diverse threat and consequence landscapes, all of which become increasingly challenging to capture when considering a large geographic extent. However, a new model or tool could enable a range of new research capabilities, including an evaluation of correlated failures and the most cost-effective mitigation options, including both long-term investments and real-time strategies for reducing response and recovery times. 


\section{References}

Anderson, Kate, Nick DiOrio, Dylan Cutler, Bob Butt, and Allison Richards. 2017. "Increasing Resiliency through Renewable Energy Microgrids." Journal of Energy Management 2(2) : 22-38. https://www.nrel.gov/docs/fy17osti/69034.pdf.

Anderson, Kate, Xiangkun Li, Sourabh Dalvi, Sean Ericson, Clayton Barrows, Caitlin Murphy, and Eliza Hotchkiss. 2020. "Integrating the Value of Electricity Resilience in Energy Planning and Operations Decisions.” Accepted by IEEE Systems Journal. DOI:10.1109/JSYST.2019.2961298

Barrows, Clayton, Aaron Bloom, Ali Ehlen, Jussi Ikaheimo, Jennie Jorgenson, Dheepak Krishnamurthy, Jessica Lau, et al. 2019. "The IEEE Reliability Test System: A Proposed 2019 Update.” IEEE Transactions on Power Systems. Early access.

https://doi.org/10.1109/TPWRS.2019.2925557.

Cohen, Stuart, Jon Becker, Dave Bielen, Maxwell Brown, Wesley Cole, Kelly Eurek, Will Frazier, et al. 2019. Regional Energy Deployment System (ReEDS) Model Documentation: Version 2018. Golden, CO: National Renewable Energy Laboratory. NREL/TP-6A20-72023. https://doi.org/10.2172/1505935.

Cole, Wesley, Nathaniel Gates, Trieu Mai, Daniel Greeg, and Paritosh Das. 2019. 2019 Standard Scenarios Report: A U.S. Electricity Sector Outlook. Golden, CO: National Renewable Energy Laboratory. NREL/TP-6A20-74110. https://www.nrel.gov/docs/fy20osti/74110.pdf.

Cole, Wesley, Will Frazier, Paul Donohoo-Vallett, Trieu Mai, and Paritosh Das. 2018. 2018 Standard Scenarios Report: A U.S. Electricity Sector Outlook. Golden, CO: National Renewable Energy Laboratory. NREL/TP-6A20-71913.

https://www.nrel.gov/docs/fy19osti/71913.pdf.

Cutler, Dylan, Dan Olis, Emma Elgqvist, Xiangkun Li, Nick Laws, Nick DiOrio, Andy Walker, and Kate Anderson. 2017. REopt: A Platform for Energy System Integration and Optimization. Golden, CO: National Renewable Energy Laboratory. NREL/TP-7A40-70022. https://doi.org/10.2172/1395453.

DHS (U.S. Department of Homeland Security). 2018. Threat and Hazard Identification and Risk Assessment (THIRA) and Stakeholder Preparedness Review (SPR) Guide: Comprehensive Preparedness Guide (CPG) 201. 3rd ed. May 2018. https://www.fema.gov/media-library-data/1527613746699fa31d9ade55988da1293192f1b18f4e3/CPG201Final20180525 508c.pdf.

- 2013. NIPP 2013: Partnering for Critical Infrastructure Security and Resilience. https://www.dhs.gov/sites/default/files/publications/national-infrastructure-protection-plan2013-508.pdf.

DHS (U.S. Department of Homeland Security), and DOE (U.S Department of Energy). 2015. Energy Sector-Specific Plan: 2015. DHS and DOE. https://www.cisa.gov/sites/default/files/publications/nipp-ssp-energy-2015-508.pdf. 
DOE (U.S. Department of Energy Office of Energy Policy and Systems Analysis). 2016. Climate Change and the Electricity Sector: Guide for Climate Change Resilience Planning. https://www.energy.gov/sites/prod/files/2016/10/f33/Climate $\% 20$ Change $\% 20$ and $\% 20$ the $\% 20$ Electricity $\% 20$ Sector $\% 20$ Guide $\% 20$ for $\% 20$ Climate $\% 20$ Change $\% 20$ Resilience $\% 20$ Planning \%20September\%202016 0.pdf

EEI (Edison Electric Institute). 2014. Before and After the Storm: Update: A Compilation of Recent Studies, Programs, and Policies Related to Storm Hardening and Resiliency. http://www.eei.org/issuesandpolicy/electricreliability/mutualassistance/Documents/Beforeand AftertheStorm.pdf.

EIS Council. 2016. Electric Infrastructure Protection (EPRO) Handbook II: Volume 1 - Fuel Resilient Fuel: Resources for Power Generation in Black Sky Events. Paul Stockton, ed. Electric Infrastructure Security (EIS) Council. ISBN 978-0-9971659-2-0. https://www.eiscouncil.org/App_Data/Upload/149e7a61-5d8e-4af3-bdbf-68dce1b832b0.pdf.

Ericson, Sean, and Lars Lisell. 2018. "A Flexible Framework for Modeling Customer Damage Functions for Power Outages.” Energy Systems Journal, 10(November 2018): 1-17. https://doi.org/10.1007/s12667-018-0314-8.

Eto, Joseph H., Kristina Hamachi LaCommare, Peter Larsen, Annika Todd, and Emily Fisher. 2012. An Examination of Temporal Trends in Electricity Reliability Based on Reports from U.S. Electric Utilities. Berkeley, CA: Ernest Orlando Lawrence Berkeley National Laboratory. https://doi.org/10.2172/1055706.

Finster, M., J. Phillips, and K. Wallace. 2016. Front-Line Resilience Perspectives: The Electric Grid. Argonne, IL: Argonne National Laboratory. ANL/GSS-16/2. https://doi.org/10.2172/134487.

FPL (Florida Power and Light). "FPL has Restored Power to All Customers Impacted by Hurricane Dorian.” FPL Newsroom. http://newsroom.fpl.com/2019-09-05-FPL-has-restoredpower-to-all-customers-impacted-by-Hurricane-Dorian.

GMLC (Grid Modernization Laboratory Consortium). 2017. Grid Modernization: Metrics Analysis (GMLC1.1) Reference Document, Version 2.1. Richland, WA: Pacific Northwest National Laboratory. https://gridmod.labworks.org/sites/default/files/resources/GMLC1\%201_Reference_Manual 2\%201 final 20170601 v4 wPNNLNo 1.pdf.

Holmes, Seth H. 2016. "Energy Model Validation for Indoor Occupant Heat Stress Analysis." Proceedings of SimBuild 6(1). https://ibpsausa.org/index.php/ibpusa/article/view/368.

Hotchkiss, Eliza, and Alex Dane. 2019. Resilience Roadmap: A Collaborative Approach to Multi-Jurisdictional Resilience Planning. Golden, CO: National Renewable Energy Laboratory. NREL/TP-6A20-73509. https://doi.org/10.2172/1530716.

Judson, Nicholas. 2013. Interdependence of the Electricity Generation System and the Natural Gas System and Implications for Energy Security. Massachusetts Institute of Technology Lincoln Laboratory. Technical Report 1173. https://apps.dtic.mil/dtic/tr/fulltext/u2/a584764.pdf. 
Keogh, Miles, and Christina Cody. 2013. Resilience in Regulated Utilities. National Association of Regulatory Utility Commissioners. https://pubs.naruc.org/pub/536F07E42354-D714-5153-7A80198A436D.

Kintner-Meyer, M., J. Homer, P. Balducci, M. Weimar, I. Shavel, M. Hagerty, N. Powers, Y. Yang, and R. Lueken. 2016. Valuation of Electric Power System Services and Technologies. Richland, WA: Pacific Northwest National Laboratory. PNNL-25633.

https://doi.org/10.2172/1393762.

LaCommare, Kristina, Peter Larsen, and Joseph Eto. 2017. Evaluating Proposed Investments in Power System Reliability and Resilience: Preliminary Results from Interviews with Public Utility Commission Staff. Lawrence Berkeley National Laboratory. LBNL-1006971. https://doi.org/10.2172/1342947.

Laws, Nicholas D., Kate Anderson, Nicholas A. DiOrio, Xiangkun Li, and Joyce McLaren. 2018. "Impacts of Valuing Resilience on Cost-Optimal PV and Storage Systems for Commercial Buildings." Renewable Energy 127(November 2018): 896-909.

https://doi.org/10.1016/j.renene.2018.05.011.

Laws, Nicholas D., et al. Forthcoming. Cost-Optimal Microgrid Planning Under Uncertain Grid Reliability.

Murphy, Sinnott, Fallaw Sowell, and Jay Apt. 2019. "A Time-Dependent Model of Generator Failures and Recoveries Captures Correlated Events and Quantifies Temperature Dependence." Applied Energy 253(November 2019): 113513.

https://doi.org/10.1016/j.apenergy.2019.113513.

National Academies of Sciences, Engineering, and Medicine. 2017. Enhancing the Resilience of the Nation's Electricity System. Washington, D.C.: The National Academies Press. https://doi.org/10.17226/24836.

Panteli, Mathaios, Dimitris N. Trakas, Elias Kyriakides, and Nikos D. Hatziargyriou. 2017. "Metrics and Quantification of Operational and Infrastructure Resilience in Power Systems." IEEE Transactions on Power Systems 32(6): 4732-4742.

https://doi.org/10.1109/TPWRS.2017.2664141.

Pearson, Candace. 2015. "Resilient Design Pilot Credits Added to LEED: Three New Pilot Credits Encourage Resilience in the New Reality of Climate Change." BuildingGreen. News brief, November 16, 2015. https://www.buildinggreen.com/newsbrief/resilient-design-pilotcredits-added-leed.

Rickerson, Wilson, Jonathan Gillis, and Marisa Bulkeley. 2019. The Value of Resilience for Distributed Energy Resources: An Overview of Current Analytical Practices. Prepared for The National Association of Regulatory Utility Commissioners. Boston, MA: Converge Strategies, LLC. https://pubs.naruc.org/pub/531AD059-9CC0-BAF6-127B-99BCB5F02198.

RMS (Risk Management Solutions). 2008. The 1998 Ice Storm: 10-Year Retrospective. RMS Special Report. http://forms2.rms.com/rs/729-DJX-565/images/ wtr 1998 ice storm 10 retrospective.pdf. 
Roege, Paul E., Zachary A. Collier, James Mancillas, John A. McDonagh, and Igor Linkov. 2014. "Metrics for Energy Resilience." Energy Policy 72: 249-256.

https://doi.org/10.1016/j.enpol.2014.04.012.

Stankovic, A., and K. Tomsovic. 2018. The Definition and Quantification of Resilience. IEEE Power and Energy Society. The Institute of Electrical and Electronics Engineers. PESTR65. http://resourcecenter.ieee-pes.org/pes/product/technical-publications/PESTR0065 04$\underline{18}$.

Stockton, Paul N. 2014. Resilience for Black Sky Days: Supplementing Reliability Metrics for Extraordinary and Hazardous Events. The National Association of Regulatory Utility Commissioners (NARUC).

https://www.sonecon.com/docs/studies/Resilience_for_Black_Sky_Days_Stockton_Sonecon FINAL ONLINE Feb5.pdf.

Viscusi, W. Kip, and Joseph E. Aldy. 2003. "The Value of a Statistical Life: A Critical Review of Market Estimates Throughout the World." Journal of Risk and Uncertainty 27(1): $5-76$.

Vugrin, Eric, Anya Castillo, and Cesar Silva-Monroy. 2017. Resilience Metrics for the Electric Power System: A Performance-Based Approach. Albuquerque, NM: Sandia National Laboratory. SAND-2017-1493. https://doi.org/10.2172/1367499.

Watson, Jean-Paul, Ross Guttromson, Cesar Silva-Monroy, Robert Jeffers, Katherine Jones, James Ellison, Charles Rath, et al. 2014. Conceptual Framework for Developing Resilience Metrics for the Electricity, Oil, and Gas Sectors in the United States. Albuquerque, NM: Sandia National Laboratory. SAND2014-18019. https://doi.org/10.2172/1177743.

White House, The. 2013. "Presidential Policy Directive: Critical Infrastructure Security and Resilience.” Presidential Policy Directive/PPD-21. Press release. February 12, 2013. https://obamawhitehouse.archives.gov/the-press-office/2013/02/12/presidential-policydirective-critical-infrastructure-security-and-resil.

Willis, Henry H., and Kathleen Loa. 2015. Measuring the Resilience of Energy Distribution Systems. Santa Monica, CA: Rand Corporation.

https://www.rand.org/content/dam/rand/pubs/research_reports/RR800/RR883/RAND_RR883 .pdf.

Wilson, Eric, Craig Christensen, Scott Horowitz, Joseph Robertson, and Jeff Maguire. 2017. Energy Efficiency Potential in the US Single-Family Housing Stock. Golden, CO: National Renewable Energy Laboratory. NREL/TP-5500-68670. https://doi.org/10.2172/1414819.

Wilson, Eric J. H., Chioke B. Harris, Joseph J. Robertson and John Agan. 2019. "Evaluating Energy Efficiency Potential in Low-Income Households: A Flexible and Granular Approach.” Energy Policy 129(June 2019): 710-737.

https://doi.org/10.1016/j.enpol.2019.01.054. 


\section{Appendix}

The Scalable Integrated Infrastructure Planning (SIIP) toolkit provides data-driven system simulations that define a set of problems that can be solved using numerical techniques.

Problems are generated by expressing model formulations against system data for infrastructure systems, including power, water, gas, buildings, thermal, transportation, and liquid fuels. SIIP collects information required for device-level modeling, including parsing capabilities, and utilizes the software, Julia, to create parametric dispatch for efficient code development and is agnostic to simulations performed. The mathematical formulations and simulation assemblies support optimization and dynamic simulation models through modular problem assembly for rapid development and extension. SIIP allows for broader modeling capabilities and expansion with interdependent systems, utilizing Julia to enable computational performance.

The SIIP Power Systems toolkit (SIIP::Power) has been used to frame the duration-dependent value of lost load (VoLL) in event forecasting (Ericson and Lisell 2018). For example, in the context of representing grid decision-making processes, most outage scenarios can be classified by the availability of event forecasts. The representation of resilience event decision-making can be further classified by the forecast duration and the likely duration of outages caused by the event. For example, extreme weather conditions can be forecast with reasonable accuracy 6-24 hours ahead of time. Forecasts can provide a reasonable estimate of when the event will occur and when crews might be able to commence recovery activities. Other event types that could stress grid resiliency may have very different forecast profiles. For example, cybersecurity attacks would likely occur without any warning. Therefore, the representation of "resiliency events" in grid decision-making models depends on the forecasting characteristics of the events themselves. To understand the ability to adjust system schedules to improve grid resiliency, the modeling of such events can be done in an adapted production cost model.

According to current understanding, VoLL depends on a variety of factors regarding both the threat type and timing, and the stakeholder whose "value" is being considered. Within a unit commitment and dispatch model framework, these factors are captured by three components: location of the bus, time of day of the event, and duration of the event. Within SIIP::Power's current capabilities, we can capture the first two components of the VoLL in a production cost model that has information of the forecasted outage. The modeling approach to simulate system recovery or dispatch after the resiliency event is very similar to solving sequential decision problems, such as in an economic dispatch problem; in particular, we assume the commitment decision are fixed, as all units may already be online or they may take too long to come online. The model solves for one time period with an initial condition and some periods of look-ahead, which informs how the outage duration-dependent cost is going to rise at each bus if its load is not served.

The current modeling approach is to build the optimization problem for each time period with a fixed initial system state, which may be right after or before the event starts, and then solve for decision variables to be made in the next hour (say $\mathrm{T}_{1}$ ) while having some information about how these actions will affect the cost incurred in future periods. Then we use the decision made for $T_{1}$ in the previous simulation as the initial conditions for the next one, and we build a similar optimization model but now we update the duration dependent VoLL, depending the outages that have occurred in $\mathrm{T}_{1}$. This way we solve for $\mathrm{T}_{2}$ and use the information to build the next simulation and so on. And in this way we can simulate the entire 
duration of the resilience event and observe how the system schedules and serves the load at each bus.

Furthermore, the load at each bus can be classified into various types (e.g., residential, commercial, and industrial). Each of these loads can have a separate curve of value/cost of lost load. Given this, the model can select the bus and type of load to serve in a compromised state. The formulation for time dependent cost of lost load (LL) - which is identical to the value of lost load, but with the opposite sign-is shown through a series of sets, including:

$g \in G$, Set of generators includes thermal and renewables

$b \in B$, Set of buses

$l \in L$, Set of lines

$t \in T$, Set of time periods

Parameters within this formulation include:

$x_{g, t_{0}}, y_{b, t_{0}}, f_{l, t_{0}}=$ Initial condition for generators dispatch levels, line flows, and lost load

$P_{g}^{\min }, P_{g}^{\max }=$ Minimum and maximum power limits for generator $g$

$R_{g}^{u p}, R_{g}^{\text {down }}=$ Ramping up and down limits for generator $g$

Flow $_{l}=$ Power flow limits for line $l$

$C_{g, t}=$ Cost of generation for generator $g$ in time $t$

$V O L L_{b, t}=$ Cost associated with lost load at bus b during hour $t$

of the outage

The variables incorporated include:

$x_{g, t}=$ Dispatch levels for generator $g$ in timeperiod $t$

$y_{b, t}=$ Non - served load at bus $b$ at time period $t$

$f_{l, t}=$ Power flow through line l in time period $t$

The objective function is represented as:

$$
\min \sum_{g, t} C_{g, t} * x_{g, t}+\sum_{b, t} V O L L_{b, t} * y_{b, t}
$$

The constraints applied included:

$$
P_{g}^{\min } \leq x_{g, t} \leq P_{g}^{\max } \quad \forall g \in G, t \in T
$$




$$
\begin{gathered}
- \text { Flow }_{l} \leq f_{l, t} \leq \text { Flow }_{l} \\
f_{l, t}=\beta_{l} *\left(\theta_{i}-\theta_{j}\right) \quad \forall l \in L, t \in T \\
\sum_{g} x_{g, t}+\sum_{l_{\text {in }}} f_{l, t}-\sum_{l_{\text {out }}} f_{l, t}=D_{t}-y_{b, t} \quad \forall b \in B, t \in T \\
x_{g, t}, y_{b, t}, f_{l, t} \geq 0
\end{gathered}
$$

Under these conditions, the solutions included set parameters with start time, horizon, and predictive (i.e., look ahead) capabilities. Challenges identified during the SIIP::Power modeling included that the model can only apply the correct cost associated with lost load in the first period, as we pass a fixed cost curve. For example, if the model decides to serve load at Bus 101 in time periods 1 and 2 but $50 \mathrm{MW}$ of load are lost in period 3, the cost associated with this would be $\mathrm{Cost}_{3}=\$ 5,000 / \mathrm{hr}$ instead of Cost $1=\$ 2,000 / \mathrm{hr}$, where the subscript of Cost is the duration of the outage. One proposed formulation to handle this issue is shown below. Revised constraints are not shown but were applied to the scenarios in SIIP::Power.

Nonlinear objective function: $=$

$$
\begin{gathered}
\min \sum_{g, t} C_{g, t} * x_{g, t}+\sum_{b, t} \text { Status }_{t}^{1} * C_{L L}^{1} * y_{b, t}+\sum_{b, t} \text { Status }_{t}^{2} * C_{L L}^{2} * y_{b, t} \cdots \\
+\sum_{b, t} \text { Status }_{t}^{n} * C_{L L}^{n} * y_{b, t}
\end{gathered}
$$

The results of the SIPP modeling indicate the cost of lost load varies with duration of the outage, as shown in the following graph.

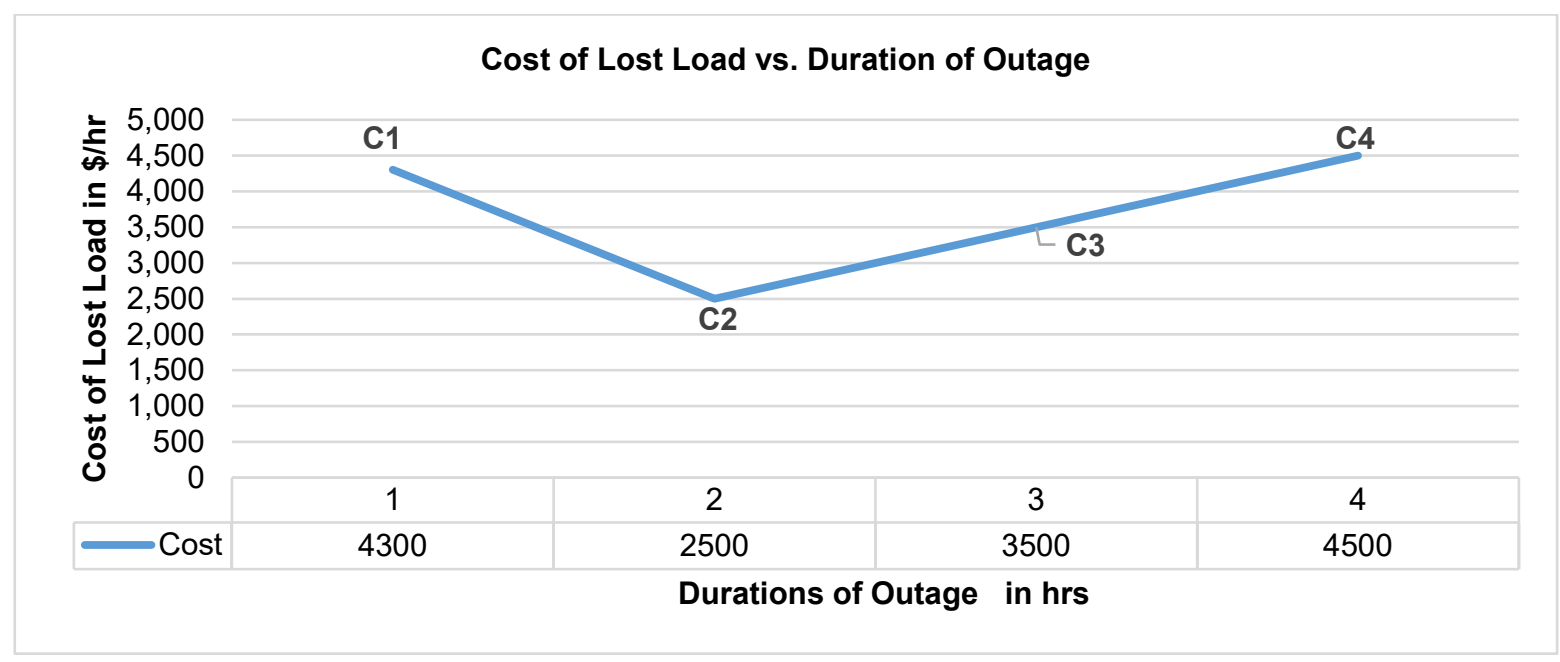

Figure A-1. Sample SIIP::Power results, indicating that the cost of lost load varies with the duration of the outage 